Full length article

\title{
Virtual worlds: A new environment for constructionist learning
}

\author{
Carina Girvan ${ }^{\mathrm{a}, \mathrm{b}, *}$, Timothy Savage \\ ${ }^{a}$ School of Social Sciences, Cardiff University, Cardiff, UK \\ ${ }^{\mathrm{b}}$ Centre for Research in IT in Education, School of Education and School of Computers Science and Statistics, Trinity College, University of Dublin, Dublin, Ireland
}

A R T I C L E I N F O

\section{Keywords:}

Constructionism

Virtual worlds

Pedagogy

Constructionist theory

Avatars

Learning

Turtle

Scratch

3D

\begin{abstract}
A B S T R A C T
Virtual worlds have the potential to provide a new environment in which to engage learners in constructionist activities. However, they were not designed for education and have features and affordances which are not found in traditional constructionist environments. These may limit the pedagogy in action and/or provide new opportunities with which to transform constructionist pedagogy in practice, but to date there has been no research on these issues. To address this, we explore constructionism in action in the virtual world Second Life. This is the first study to examine the theoretical alignment of pedagogy and technology in practice. An exploratory case study of a purpose-built constructionist learning experience was conducted. The experience was designed based on the theoretical alignment of pedagogy and technology and implemented with 24 postgraduate students over four weeks. Open non-directive interviews, chat logs, constructed artefacts, learners' written reflections and observations were collected and analyzed using the constant comparative approach. The findings provide insights into how learners engage in meaningful artefact construction, highlight the role of avatars and draw attention to the importance of the designed space. New opportunities for distributed constructionism are identified. We conclude that virtual worlds are effective environments for constructionist learning.
\end{abstract}

\section{Introduction}

Virtual worlds have the potential to provide an exciting environment to engage in transformative constructionist learning activities. With inbuilt construction and programming tools and without the boundaries of gaming environments, learners can engage in a process of bricolage (an incremental process of trying and testing, rather than following a pre-existing design (Papert, 1991)), to construct personally meaningful, shareable 3D artefacts in order to explore, test and extend their understanding, in situ (Ackerman, 2004) with other learners. Yet there is a paucity of literature on constructionism in virtual worlds.

Constructionism is rarely identified as the pedagogical underpinning for the design of learning experiences in virtual worlds. Responding to the critique by Savin-Baden and others that learning in virtual worlds lacks clear pedagogical underpinning (2008; 2011), there is increasing reference to pedagogical theory within the literature, although it is often unclear how those theories have been used to inform the design of the learning activity. While Livingstone, Scullion, and Creechan (2013) suggest that previously reported learning activities could typically be characterized as constructionist as they require learners to create something in the virtual world, it is often not clear how the broader features of constructionism are designed for.
We argue that simply creating an object in a virtual world is not a constructionist activity. For example, earlier work by Girvan and Savage (2010) which involved the creation of books by groups of learners as part of a communal constructivist learning activity, required learners to engage in much of the 'construction' of their artefacts outside the virtual world, while their knowledge was constructed within the virtual world. Their final artefacts of knowledge were put on display and shared with subsequent groups but there was no evidence to suggest that learners built and rebuilt their artefacts as their understanding developed, as expected in a constructionist activity. Rather they created and shared their books after they had already collaboratively developed their understanding and used the books as a medium to communicate their new knowledge, as we would expect in a communal constructivist activity (Holmes, Tangney, FitzGibbon, Savage, \& Mehan, 2001).

A notable exception to our critique is the work of Dreher, Reiners, Dreher, and Dreher (2009; 2009b) who describe the construction of inworld artefacts through which learners engage in exploring and extending their understanding. However, it is rare for authors to report on how constructionist learning was supported in the design of the learning experience and there is typically no or only a vague indication as to how the specific features of the technology support constructionist learning activities (e.g. Fominykh, Prasolova-Førland, \& Divitini, 2014;

\footnotetext{
* Corresponding author. School of Social Sciences, Cardiff University Glamorgan Building, King Edward VII Avenue, Cardiff, Wales, CF10 3WT, UK.

E-mail address: girvanc@cardiff.ac.uk (C. Girvan).
} 
Grivokostopoulou, Perikos, Kovas, \& Hatzilygeroudis, 2016; Niemeyer \& Gerber, 2015).

More recently, Pellas and Peroutseas (2016) provide a detailed account of the design of their learning activity, building on our previously published work (Girvan, 2014, p. p367; Girvan, Tangney, \& Savage, 2013). Underpinned by constructionism, they developed a game-like learning activity within a virtual world to engage high-school students in programming. Blending constructionism with game-based learning assumes a 'winning' state which implies an end to the activity. Constructionism, however, focuses on exploring, testing and extending understanding through personally meaningful and shareable artefacts and may therefore be considered at odds with game-based, goal-orientated approaches. Another important aspect of the pedagogical theory is that learners should create something personally meaningful through a bricolage approach, yet students in this activity were given a series of closed challenges to complete (to use Scratch 4 OpenSim to create a variety of Greek letters).

While we are starting to see more rigorous accounts of the design of constructionist learning activities in virtual worlds, key features of the pedagogy are still often overlooked. Additionally, we do not see any discussion of the potential impact of the features and perceived educational affordances of the technology on the pedagogy. This is not specific to virtual worlds or constructionism, however environments which are not purpose built to support constructionist learning, such as virtual worlds, will have features and affordances that provide both opportunities and constraints on the implementation of the pedagogy. These may not be easily recognized as the majority of computer-based, virtual constructionist learning activities (as opposed to physical constructionist tools such as robots) use purpose-built microworld environments (such as Scratch) which are designed with constructionist ideas in mind. The alignment of constructionism with emerging technologies and the identification of how the education affordances of the technology impact on the constructionist pedagogy adds further complexity to attempts to understand the practical implications of using constructionist pedagogical theory in virtual worlds.

Within a virtual world, learners inhabit a shared space and are represented as avatars. While there may be parallels to the physical world regarding the ways in which learners act and interact in the virtual world, we should be curious about the ways in which these and other features and affordances of the technology transform (or not) the experience of the learner, in both positive and negative ways.

There are questions about the implications of using virtual worlds for constructionist learning in practice. Importantly we need to consider how learners engage with and within the technology, in ways which support or limit constructionist learning. There are no previously reported findings that enhance our understanding of the pedagogy in action within virtual worlds. This includes if and how the features of the pedagogy emerge in practice as learners engage. Existing literature tends to focus on learning outcomes, whether in terms of summative assessment of skills and knowledge, or motivation and engagement. Yet, while we might presume that the pedagogic features will emerge if they are designed for, there is no evidence for this and no understanding of how the perceived affordances of the technology might constrain the pedagogy or provide new opportunities unavailable in other constructionist environments (whether digital or physical i.e. Scratch and Lego Mindstorms). If we are to support educators, learning technologists and designers to consider and use virtual worlds for constructionist learning activities, or consider and use constructionist theory in the design of learning experiences in virtual worlds; we need to develop an understanding of the pedagogy in action within virtual worlds and use this to advance the theoretical alignment of technology and pedagogy.

Accordingly, the primary aim of the research presented in this paper is to explore constructionism in action in virtual worlds through an exploratory case study. Participants engaged in a learning experience built upon an understanding and analysis of the alignment between the features of constructionism and the perceived educational affordances of virtual worlds. This research analyses whether the perceived educational affordances constrain or support the learners' experience and whether the proposed alignment of pedagogy and technology is sufficient and purposeful in the light of an authentic implementation.

\section{Theoretical framing}

\subsection{Constructionism}

Constructionism focuses on the active construction of knowledge through the creation of physical artefacts to support learning. By constructing personally meaningful and shareable artefacts, learners are provided with an opportunity actively to explore, test and extend their understanding (Papert, 1991). These artefacts may develop in-situ (Ackerman, 2004) and through a process of bricolage (an incremental process of trying and testing, adding to and taking from the artefact), rather than following a pre-existing design (Papert, ibid).

Some of the most common and well-known constructionist tools are digital (e.g. Turtle Graphics and Scratch). The computer provides access to objects and environments that can support concrete engagement with ideas that would otherwise require formal teaching. Thus, the computer is introduced as a central component of constructionist learning experiences to provide access to materials otherwise unavailable to the learner (Papert, 1980). We suggest that currently, networked computers and mobile devices are a part of most people's everyday lives and it is the software/hardware and our interactions with, within and through the technology as part of constructionist learning experiences that requires investigation.

Constructionist tools are typically characterized as low-floor (easy to use), high-ceiling (powerful) and designed to support learners engaged in construction, exploration and investigation (Feurzeig, 2007). Objects such as Turtle (physical or on-screen graphics) provide learners with an 'objectto-think-with' (Papert, 1991), allowing them to code rapidly, observe, reflect and revise, supporting the idea of exploring, testing and extending understanding through engagement with an object. Turtle Graphics, and more recently Scratch, provide learners with a digital environment within which they can control and create objects on the screen. The wider the variety of artefacts that can be created in these environments, the more likely they are to reflect the interests and learning preferences of their users, thus 'widening the walls' (Resnick et al., 2009) and therefore they are more likely to be personally meaningful.

While constructionism provides a basis for understanding the ways in which materials in the learner's environment can support learning, unlike constructivism, it also provides an educational approach situated in a social context (Butler, 2007; Kafai, 2006, p. pp35; Kafai \& Resnick, 1996). The emphasis is therefore not on internal knowledge construction but external representation of that understanding to be shared with others.

Extending the central ideas of constructionism, Resnick (1996) describes 'distributed constructionism', as the design and construction of artefacts by more than one person. Drawing on 'distributed cognition' (Salomon, 1994), distributed constructionism focuses on the use of computer networks to facilitate interactions between people and in turn, knowledge construction. However, unlike knowledge building, distributed constructionism involves the construction of meaningful artefacts and not just the sharing of information.

Resnick (1996) describes distributed constructionism as taking three forms: discussing constructions, for example on an online forum; sharing constructions, for example uploading an artefact which others can copy and reuse; and collaborating on constructions. These provide opportunities to discuss, share and collaborate on constructions. As with other constructionist activities reported in the literature, distributed constructionism is facilitated by technology. However, by engaging in a constructionist learning experience the technology should become 'invisible' (Papert, 1980s; 1991; Bruckman \& Resnick, 1996).

\subsection{Virtual worlds}

Unlike traditional constructionist environments such as Turtle 
Graphics, virtual worlds have not been purpose built for learning, let alone for constructionist learning activities. However, they provide an environment which users can create and modify objects through construction and programming tools, and through this they can be appropriated for educational purposes.

Across the literature there are various technologies which are referred to as virtual worlds. Here we follow Girvan's (2018) definition of virtual worlds as "shared, simulated spaces which are inhabited and shaped by their inhabitants who are represented as avatars. These avatars mediate our experience of this space as we move, interact with objects and interact with others, with whom we construct a shared understanding of the world at that time." (p.1099).

"What makes [virtual worlds] distinct from the material or physical world are the types of experience available for the user afforded by the combination of different technical features, most notably the avatar" (Girvan, ibid, p1093). Avatars are one of several features of the technology which give rise to a range of perceived educational affordances, which can provide both opportunities and constraints to learning.

Virtual worlds provide synchronous collaborative social spaces that can be utilised for a range of authentic learning experiences and cater for a range of learners (Gregory et al., 2015). Within higher education, virtual worlds have been applied in virtual lectures, virtual laboratories, virtual field trips, simulations, in-world creations, gaming, assessment and socialisation (Ghanbarzadeh \& Ghapanchi, 2018).

Fig. 1 illustrates some of the ways in which the literature identifies features of the technology which give rise to various perceived educational affordances. Combined, these perceived educational affordances allow other affordances to emerge and these five (represented in bold in Fig. 1) are used to align features of the pedagogy and affordances of the technology in 2.3 below.

How the tools of the virtual world and how the affordances are leveraged by teachers or others who design learning experiences in virtual worlds, and in turn how learners engage with and experience these will vary on an individual basis. Factors beyond the virtual world, whether associated with the individual or the physical learning environment, may or may not have an impact. For example, Warden, Stanworth, and Chang (2016) examined the extent to which gaming experience and gender influence the sense of presence in a virtual world learning environment. While their findings revealed no significant impact, Grinberg, Careaga, Mehl, and O'Connor (2014) found that social experiences within the virtual world did have a significant impact on a sense of immersion.

\subsection{Theoretical alignment of pedagogy and technology}

Constructionism is a potentially appropriate pedagogy for use in virtual worlds because it leverages a wide range of the perceived educational affordances as outlined in Table 1.
Table 1

Alignment of perceived educational affordances of virtual worlds and the features of constructionism.

\begin{tabular}{lll}
\hline Constructionism & Perceived educational affordances \\
\hline $\begin{array}{l}\text { Construct personally meaningful } \\
\text { artefacts }\end{array}$ & $\begin{array}{l}\text { Creation of persistent } \\
\text { objects }\end{array}$ & Construction \\
$\begin{array}{l}\text { Actively explore, test and extend } \\
\text { understanding }\end{array}$ & & \\
$\begin{array}{l}\text { Opportunity to program } \\
\text { Shareable artefact } \\
\text { Bricolage }\end{array}$ & & Programming \\
$\begin{array}{l}\text { In-situ } \\
\text { 'Invisible' technology } \\
\text { Collaborating on constructions }\end{array}$ & Flexibility & Persistence \\
\hline
\end{tabular}

A constructionist learning experience can leverage the virtual world's technology to allow the construction of persistent artefacts. In addition, Hoyles, Noss, and Adamson (2002) describe the programming of objects as an important aspect of constructionism, which would also utilise the programming aspect of the creation of persistent objects in virtual worlds. The fact that these objects remain in the virtual world (i.e. they persist) when the creator is not there, allows learners to collaborate and share asynchronously. Collaborating on constructions should be supported by providing opportunities for collaborative learning, while embodied social presence (through avatars) may support an in-situ learning experience. The emphasis on bricolage could be supported by the perceived educational affordance of flexibility, allowing learners to construct, reconstruct and start afresh any artefact. Finally, immersion may support the sense of an 'invisible' technology, this may be particularly likely from the level of engrossment, at which point controls are described as becoming invisible (Brown \& Cairns, 2004, p. pp1279).

Constructionist environments, such as Scratch, are often referred to as 'microworlds' described by Ackerman and Strohecker as "carefully crafted artificial settings for creative exploration" (1999, p.14). Computer-based microworlds are designed to enhance the most important features of a given phenomenon and remove those that might distract the learner by "muddying" the outcome (Edwards, 1998). By comparison virtual worlds neither enhance the most important features for learning nor remove the distracting ones. However, they do provide educators with control over aspects of the environment, for example whether gravity is on or off. Consequently, if an educator wishes to provide a construction environment without natural physical laws in Second Life, they can.

In contrast to purpose-built microworlds, virtual worlds do not provide learners with low-floor construction or programming tools. Instead the inbuilt tools present the novice with a steep learning curve (Cheal, 2009; Dickey, 2005; Sanchez, 2007) preventing them from

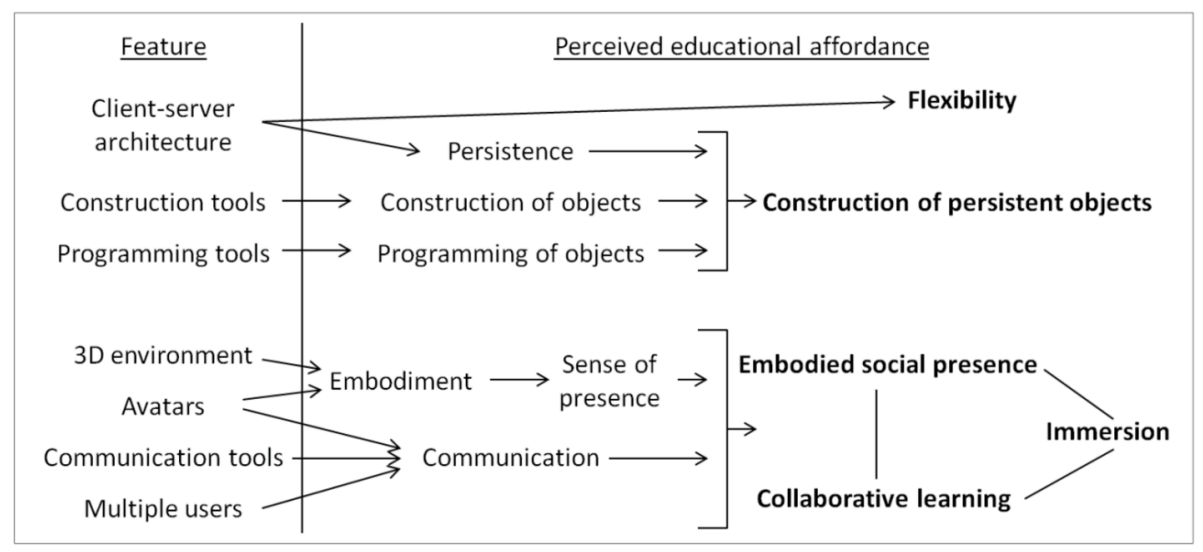

Fig. 1. Features and perceived educational affordances of virtual worlds. 
easily creating and programming objects; discouraging engagement; and ultimately the ability to construct personally meaningful artefacts, a core feature of constructionism. To address this problem, the authors developed SLurtles (programmable turtle robots) as constructionist objects-to-think-with and build with in the virtual world of Second Life (Girvan et al., 2013).

SLurtles (Second Life turtles) pay homage to the legacy of Turtle Graphics, except that instead of being programmable objects that create 2 dimensional lines as they move, SLurtles create 3 dimensional, persistent virtual objects within the virtual world of Second Life as they move. SLurtles are programmed using the block-based Scratch 4 Second Life (S4SL) interface, developed by Eric Rosenbaum (2008). The combination of the SLurtle and S4SL provides a user with a low-floor programming and construction tool.

\section{Method}

\subsection{Research design}

The aim of this research is to explore constructionism in action in virtual worlds through the analysis of an authentic constructionist learning experience designed based on the alignment of the features of constructionism and the perceived educational affordances of virtual worlds. Specifically, it examines how the features of the pedagogy emerge and how the affordances are perceived by the learners to constrain or support their experience of constructionist learning. This allows us to critique the proposed alignment of technology and pedagogy, identifying implications for both theory and practice.

Learning environments however, whether in the physical or virtual world, are messy places for research and it is this complexity that needs to be captured to address the core aim of developing an understanding of constructionism in action in virtual worlds.

Case studies are particularly powerful for developing an understanding of a phenomenon under study as they provide a rich description for the in-depth exploration of a specific learning activity in action. With the dearth of existing literature and theory in the area, an exploratory case study approach is used to identify and elaborate on key concepts in an otherwise broad field (Yin, 2003; 2009).

\subsection{Participants}

24 learners participated in a constructionist learning experience using SLurtles over four weeks, as part of a part-time post-graduate course in technology and learning at a university. In a face-to-face context, learners were given information about the research, their proposed involvement in it and their right to withdraw. Then they were given an opportunity to ask questions of the researcher and instructor.

19 of the students self-reported having little or no previous programming experience. Only four had experience of using Second Life before the course. They were aged between 24 and 55 and included 15 female and 9 male participants. During the learning activity they were placed in pairs by the instructor. There was 1 all-male pair, 4 all-female pairs and 7 mixed pairs. The 5 learners with previous programming experience were paired with learners who had little or none.

As learners would be participating in the learning activity at distance from one-another and the instructor, using pseudo-anonymous avatars, a key ethical issue was that of identity. The identity of the user behind the avatar could be further complicated by the use of alternative avatars ('alts') (Girvan \& Savage, 2012). "Alts" are avatars created by the user in addition to their primary (or "main") avatar. To address this issue, access to the learning environment was limited to one avatar per participant (no "alts"), participant and avatar names were held by the instructors and participants were informed of the risks of sharing an avatar with other people. All 24 learners gave their informed consent. Ethical approval was granted by the author's institution which was also the location of the study.

\subsection{Activity design}

To interpret the findings presented, and as part of the case study reporting, this section describes the design of the learning experience and how it was informed by constructionist principles of learning.

\subsubsection{Activity design principles}

The theoretical alignment of pedagogy and technology presented in 2.3 was considered and a series of activity design principles for the learning activity identified. For example, the alignment between the constructionist principle of collaboration and the perceived educational affordance of collaborative learning within virtual worlds led to the design principle that the activity exploring these alignments must include both a reason and an opportunity to collaborate as a fundamental aspect of the experience. Therefore, based on the theoretical alignment of pedagogy and technology presented in 2.3, a series of design principles were identified (Table 2).

\subsubsection{Context of the implementation}

The learning activity was implemented as part of a module for postgraduate learners on a taught Masters in technology and learning. The course is taken over two years part-time to support the participation of practicing teachers and other professionals. It is underpinned by communal constructivism (Holmes et al., 2001) and focuses on technologymediated transformative learning experiences (Mezirow, 1996). While the course content has changed over time it broadly introduces learners to pedagogical theories, various technologies, critical reflection, collaboration, design principles and research.

The module for which the learning experience was designed is worth 10 credits and has no formal pre-requisites. Teaching and learning activities center around a mixture of formal lectures (which are kept to a minimum), practical sessions and workshops. The aim of the module is to raise awareness and develop understanding of a number of innovative technologies used in the area of technology and learning through engaging in concrete experiences with these technologies. A typical cohort of learners would include those working in formal K-12 education as teachers and those involved in various roles in other workplaces including instructional designers and trainers.

The learning experience was designed with the course team and

Table 2

Design principles.

\begin{tabular}{|c|c|c|c|}
\hline Constructionism & \multicolumn{2}{|c|}{ Perceived educational affordances } & Design principles \\
\hline $\begin{array}{l}\text { Construct personally meaningful artefacts } \\
\text { Actively explore, test and extend understanding }\end{array}$ & $\begin{array}{l}\text { Creation of persistent } \\
\text { objects }\end{array}$ & Construction & $\begin{array}{l}\text { (Semi-) open task, using SLurtles and S4SL (to lower barriers to engagement) to } \\
\text { construct artefacts. }\end{array}$ \\
\hline Opportunity to programme & & Programming & \\
\hline Shareable artefact & & Persistence & \\
\hline Bricolage & Flexibility & & Time to engage in an extended process of construction. \\
\hline In-situ & Embodied social presence & & Shared learning space. \\
\hline 'Invisible' technology & Immersion & & Familiarisation with technology. \\
\hline Collaborating on constructions & Collaborative learning & & Reason and opportunity to collaborate. \\
\hline
\end{tabular}


implemented in Second Life. The main lecturer on the module is experienced in the implementation of constructionist learning experiences. However, as he had no previous experience of Second Life, the learning experience was designed in keeping with previous constructionist activities that he had run on the course which involved learners engaging with Lego Mindstorms kits to create an interactive robot and the design of games in Scratch.

As part of the module, learners had already been introduced to constructionist theory and the learning experience at the heart of this study was presented to them as an opportunity to experience a constructionist learning activity for themselves. Learners participated in the SLurtle-based learning experience over 4 weeks as part of their course. The intended outcomes were for learners to (1) experience a constructionist learning activity; and (2) gain an understanding of programming.

The learning activity had four phases; orientation, learning event/ workshop, the open task as assessment, and group presentations (Fig. 2).

Prior to the first learning event, an informal orientation to the virtual world was organized during which learners (at distance and typically from home) created their avatars and joined the course team in the virtual world and navigated to the course island where they completed a number of orientation activities designed to introduce them to movement and camera controls as well as communication tools, in order to familiarize themselves with the technology. From this point onwards, the primary researcher was present at all learning events and supported learners, both face-to-face and online.

The first structured learning event involved a face-to-face, half-day workshop to introduce learners to SLurtles and S4SL. Following an initial demonstration of SLurtles, learners worked on their own and later in their pairs to program SLurtles to complete a series of increasingly difficult challenges. Having worked out how to program their SLurtle to move forward 1 meter, the challenges required learners to program their SLurtles to create increasingly complex objects in the virtual world (Fig. 3), before moving on to programming those objects to be interactive.

After exploring some of the basic functionality and demonstrate their ability to use SLurtles and S4SL, learners were set an open task to complete as part of their assessment. The task required each pair to collaborate on the creation of an interactive installation; programming SLurtles to create the installation and using S4SL to program the installation to be interactive. After four weeks, the learners presented their installations (their artefacts of learning) and reflections on the experience to the class.

There were no formal teaching inputs over the four weeks. Informally groups of learners could meet with one of the instructors in the virtual world to discuss their progress and gain technical support. Due to the 'always on' nature of Second Life, learners were able to engage in the activity at any time or place that suited them. As the learners were only required to attend the institution part-time, this opportunity to collaborate at distance and at a convenient time was important. They could meet face-to-face, online or a combination of these depending on their preferences.

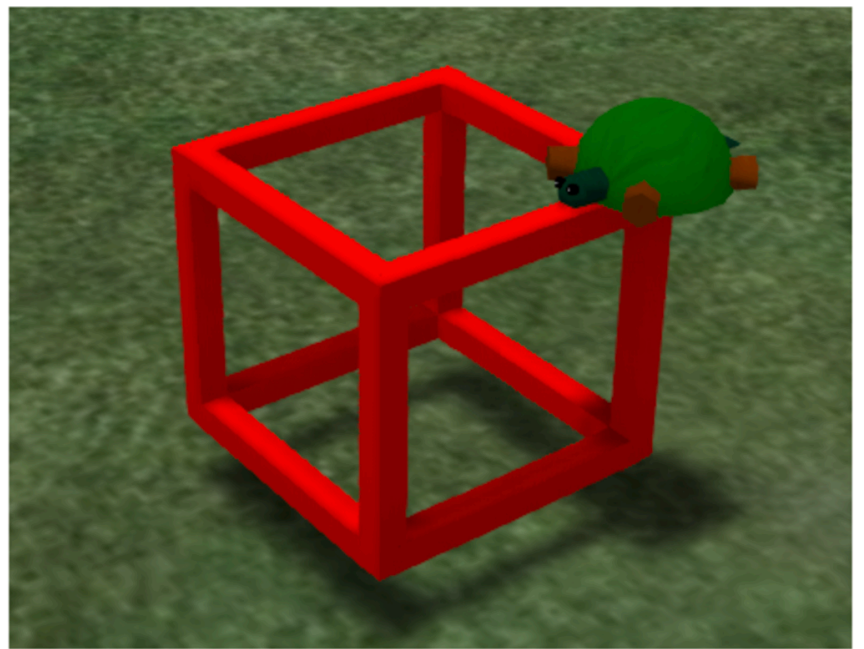

Fig. 3. Example of the final construction challenge completed, before programming objects to be interactive.

As the learners' artefacts were to be assessed as part of an accredited course, each pair was provided with a discrete learning space with clear boundaries in the form of an empty $40 \times 40 \mathrm{~m}$ platform (Fig. 4) on the island, in which they were required to create their installation. All the group's platforms were adjacent to each other and connected by walkways for those who did not wish to fly. Each platform was bordered by transparent walls to prevent avatars from falling off them as well as allowing visibility into each pair's installation space. The open and public (among the group) nature of the space meant that learners could be influenced by observing artefacts constructed by others (Girvan, 2014, p. p367) and supporting collaboration and socialisation with the wider group. This combination of a dedicated construction space for each pair alongside their classmates and completely visible to them provided a publicly accessible, discrete learning space within an access-controlled island allowing only class participants access.

Below the platforms were two SLurtle collection points at which learners could choose SLurtles based on the shape of block they wished to create (see Girvan, Tangney \& Savage, 2013). The initial orientation activities remained on the island, together with spaces designed to facilitate meetings.

\subsection{Data collection}

Open, non-directive interviews provided the primary source of data for analysis and were supplemented by screen captures, observational notes, in-world chat logs and the artefacts created by the learners as part of the experience. These supplemental data sets were considered secondary data sources due to issues outlined below, and were used primarily to support or refute emergent findings from the constant comparative analysis of the interviews.

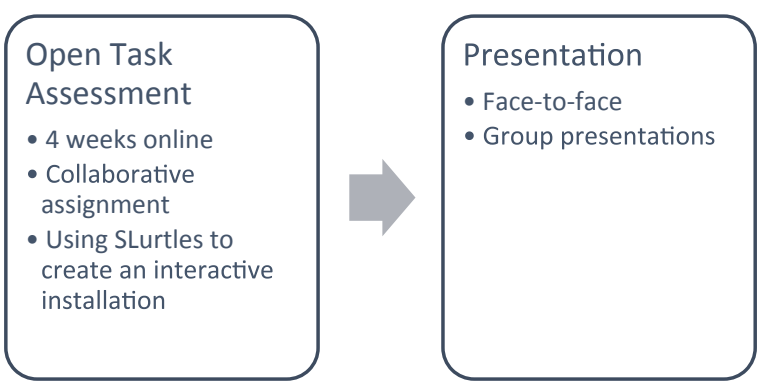

Fig. 2. Four phases of learning activity implementation. 


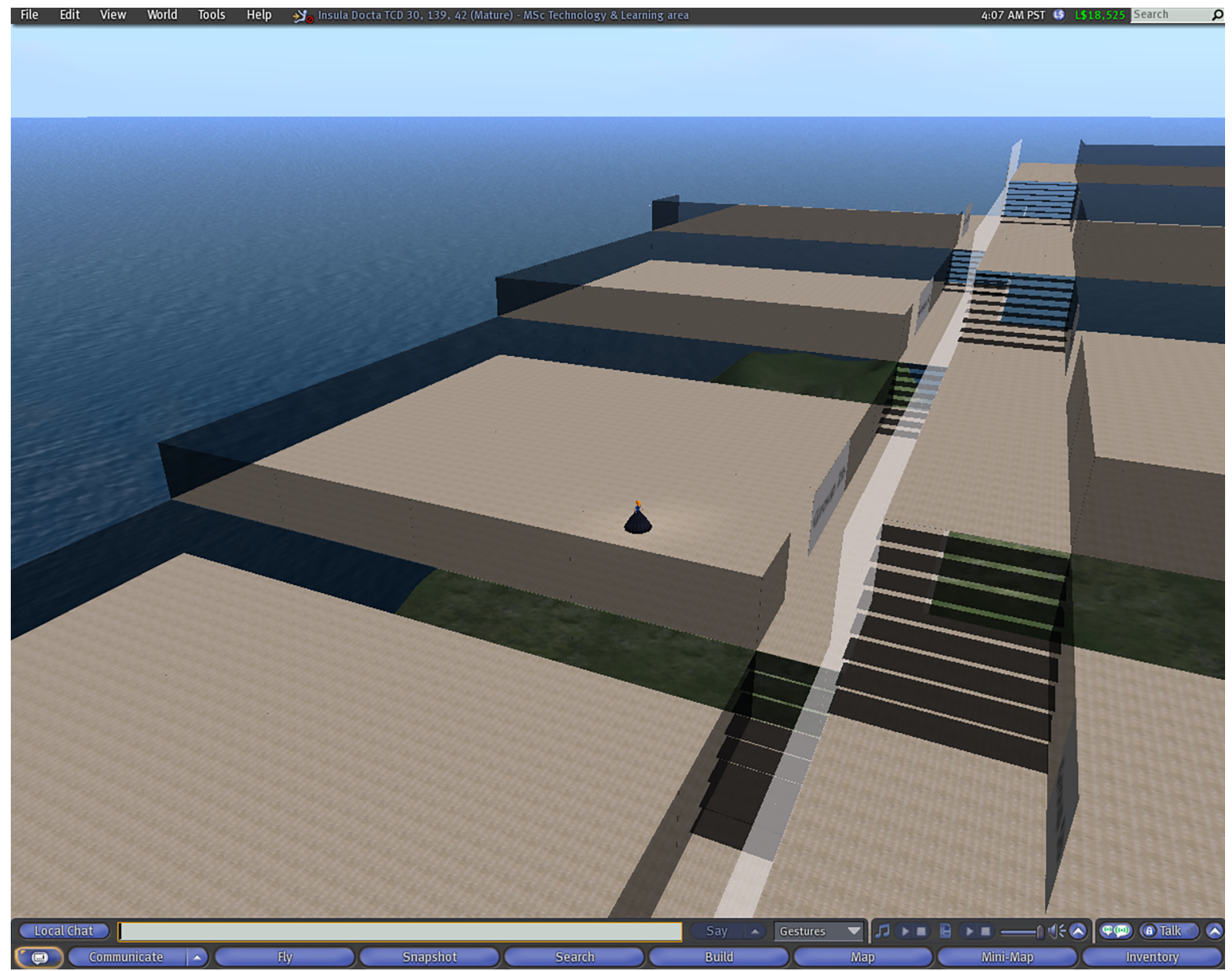

Fig. 4. Empty installation spaces with avatar prior to the activity.

An opportunistic sample of 14 took part in one-to-one interviews which were conducted in the weeks following the learning activity in either the virtual world using voice communication or face-to-face and lasted between 30 and $80 \mathrm{~min}$. While the mix of medium and location may influence the data collected, some participants were only accessible to the researchers via the virtual world and so these two approaches were used to increase participation. Audio recordings of the interviews were transcribed with names of participants and their avatars anonymised. Seven of the 14 participants interviewed were male and seven female; one was in an all-male pair, two were in all-female pairs (not from the same pair) and the remaining 11 were in mixedgender pairs, only one pair of learners both participated in the interviews (and these were the first two interviews to be analyzed); three had previous experience of programming and four had previous experience of Second Life.

Observational notes were made during and immediately after learning events. However, due to the always-on nature of the virtual world and the unrestricted opportunities that learners had to access and participate in the activity (at any time and from any place), it was difficult to observe directly participants' actions during the main task. While there were opportunities to observe learners' avatars and their corresponding in-world actions, these were limited for the same reason. Thus, chat logs of the learners' text-based conversations were recorded by the participants themselves. However, these were limited as not all participants were able to use these tools. Screen capture software was considered, but this required learners to remember to launch the software and record their screens during activities. Additional constraints were the size of files created and the processing power required both to record and engage with the virtual world. As a result, participant screen capture was not a viable approach on this occasion, although the researchers did use this to record activities from their avatar's perspective whilst in the virtual world.

In addition to observational notes, the final artefacts created by each pair (12), as well as their group (12) and individual (24) written reflections were collected after the class presentation. These were treated as corroboratory data as they were created for a specific purpose (that of assessment) and an intended audience (the course instructor) and therefore would not be without bias (Yin, 2009).

\subsection{Data analysis}

The primary analytic strategy was to develop a case description and, from this, apply the secondary analytic strategy to generate theoretical propositions. To achieve this within an exploratory case study, the constant comparative method was used (Glaser \& Strauss, 1967; Merriam, 1998). This analytical method has developed from its original roots within grounded theory through subsequent development and adoption among other types of qualitative research (Boeije, 2002). The process of comparison occurs throughout the whole process of analysis from coding to the forming and delimiting of categories and analyzing the relationships between them. Whilst this is a messy, non-linear process (see Fig. 5), for the purposes of clarity the following presents a linear description, detailing the analysis process.

Data analysis began with the open coding of the first interview. Through analysis of subsequent interviews and comparison with the interviews already analyzed, new codes emerged, some codes became 


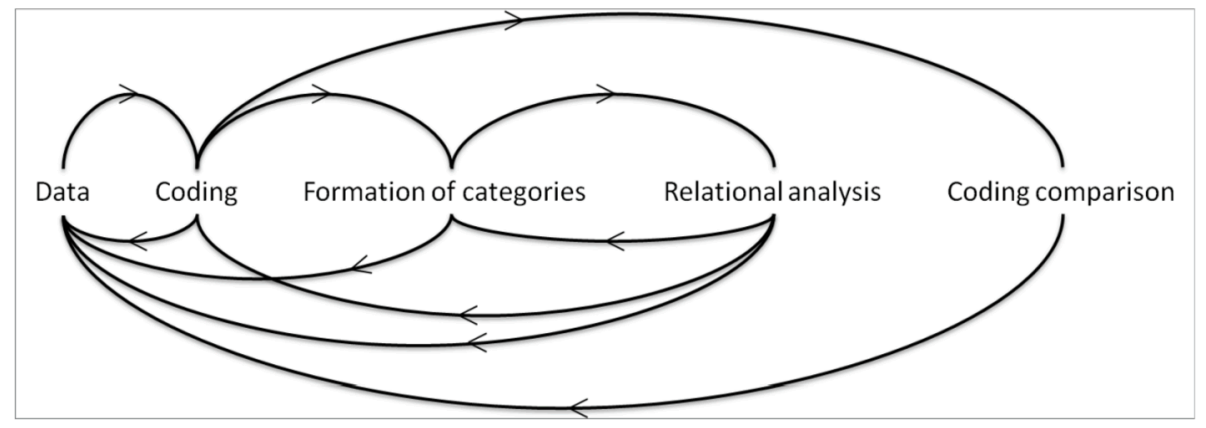

Fig. 5. The messy process of data analysis (Girvan et al., 2013).

redundant and dimensions began to develop (Cohen, Manion, \& Morrison, 2007; Creswell, 2003). Emergent findings shaped the flow of the data analysis which included the generation and reduction of codes, formation of tentative categories, relational analysis and internal coding comparison (illustrated in Fig. 5). The analysis was supported using computer assisted qualitative data analysis software (QSR - Nvivo 8).

As the first two interviews were with learners who participated in a pair together, it is perhaps unsurprising that from an initial generation of 74 codes only 25 new codes were generated in the analysis of the second interview. Analysis of subsequent interviews resulted in the generation of up to 63 new codes. Following the apparent saturation of codes in the seventh interview, categories and sub-categories were developed from the original codes through an iterative process which aimed to produce efficient categories: exhaustive, mutually exclusive, sensitizing and conceptually congruent (Merriam, 1998). The remaining interviews were then analyzed for evidence to support or refute the categories and sub-categories, whilst remaining open to emergent codes. Following this, further refinement of the categories took place. This process was repeated using the learner's reflections, observational notes and artefacts of learning, as secondary data sources to provide supporting or refuting evidence.

The codes within each category and sub-category are presented in the Appendix, however, as the philosophical underpinnings of phenomenology and the constant comparative approach downplay the significance of mathematical interpretation, the numerical coding data was excluded from the study and the interpretations. As Strauss and Corbin note (1998, p. 11) their approach is "a nonmathematical process of interpretation, carried out for the purpose of discovering concepts and relationships in raw data and then organizing these into a theoretical explanatory scheme."

As a single researcher conducted the analysis, actions were taken to provide an internal validity check on the coding process. After the seventh interview had been coded, a new identifier was created in the QSR - Nvivo file. This allowed the coder to recode the interviews without visibility of the codes from the first coding iteration. Cohen's Kappa calculations were then run between the two sets of codes to generate a statistical measure of agreement or error between the coding runs. The Kappa result indicated which codes had been used reliably within the interview. For example, the code avatar supports socialising had a Kappa of 1 indicating that the code was applied by the researcher to the same section of text at the start of the data analysis process and at the end. Thus, this code was used reliably. By comparison, the code develop idea had a Kappa of 0.3578 , suggesting that this code was applied quite differently from the start of the analysis to the end. With such codes the breakdown of percentage agreement and disagreement was used to re-examine the researcher's coding. While Cohen's Kappa coefficient provides an indicator of reliability, it is not sufficient on its own. Thus, the statistical analysis prompted a review of the researcher's use of codes during the coding process which involved reexamining references and identifying overlap between codes resulting in a reduction of codes. Following this process of internal review, the final seven interviews were coded with an improved understanding of how each code should be applied.

During the development of a final set of categories, two further tests of validity were used: member checking with two interview participants and peer validation with colleagues.

\section{Findings}

This study explores Constructionism as a pedagogy in action within virtual worlds, through a purpose designed learning activity. This section presents the findings of the constant comparison analysis, with categories acting as sub-sections: 'Group work', 'Learning environment', 'Design' and 'Learning'. A further category 'Thinking' which mostly focuses on learners' use of SLurtles during the learning activity has previously been reported by the authors (Girvan et al., 2013). For each category, the relationships within it to and between sub-categories are illustrated to support communication of the findings. Additionally, for transparency, codes within categories are in bold.

\subsection{Group work}

As learners were required to work in pairs on the assignment, it is perhaps unsurprising that 'Group Work' emerged as a category. However, within it there are three key sub-categories: 'Imbalance'; 'Communication'; and 'Collaboration' (Fig. 6).

\subsubsection{Imbalance}

In six of the first seven interviews analyzed, there was mention of some form of 'imbalance' within groups and this was explored in the relational analysis. Learners perceived an imbalance in knowledge of programming between themselves and their partner, often identified through the stronger programmer dominating and increasing independent work. For example, in an individual reflection one participant stated: "I think $3 a 1$ at first was a little worried about my knowledge especially as when she arrived into Second Life for our first meeting I had spent a lot of time playing." (3a2 reflective journal entry). The result of a perceived imbalance was a lack of collaboration and communication which often led to a sense of loneliness "see I did find it frustrating, I was saying I was lonely over here." (2a1 interview). Interestingly in these situations, both experienced and novice programmers described being limited by their partner.

Learners described recognizing this imbalance and deciding to take action in a number of ways such as insisting on an increase in communication and discussion. With an increase in communication, collaboration changed: "I suppose then, we kind of did everything together. There was nothing, nobody did one thing on their own then after that. And we kind of learned from each other" (3a2 interview). Learners described actively learning from their partner which helped to address the initial imbalance and their group began to "work well". 


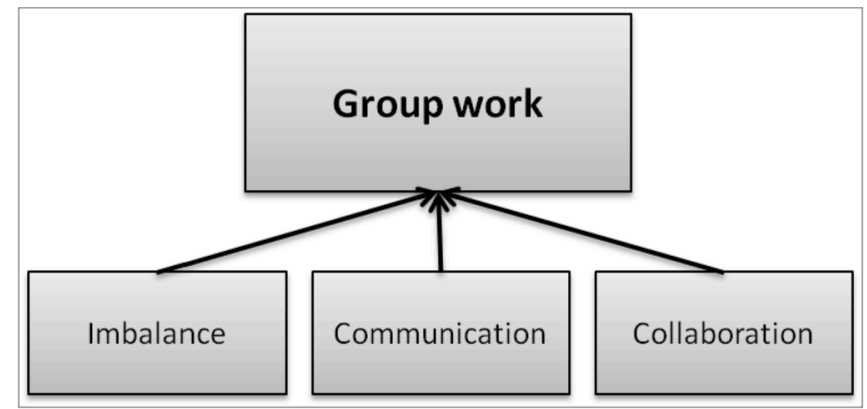

Fig. 6. Representation of 'Group work' category.

\subsubsection{Communication}

Communication was an important aspect of how groups worked together: "we worked very well together. I think once initially we had the conversation around the different levels, I suppose, of competence in relation to programming, and I suppose my need for him to slow down a bit; once we had that conversation we worked very well together." (3a1 interview).

Across reflections, interviews and chat logs there was evidence of participants using text-based chat, Second Life voice and external tools such as Skype to communicate within the group. While some participants described the text-based chat tools as sufficient for collaboration, others were frustrated by them: "I was trying to explain to her where I thought the code was going wrong, and it was taking so long over, to get the message across. And then also, I felt that the message I was putting across might have seemed like I was telling her, or a bit, if you read the text, you could see it could be, depends on what way the person takes it" (3a2 interview). Another participant described the confusion which resulted from the response speed of each participant in the text chat at the start of the project: "kind of talking about one thing and then going on to the other, just kind of thinking aloud, and what was happening was there was two or three different conversations happening simultaneously, and you were answering one thing and next of all, next they were replying back to what you said 2 min ago" (5b1 interview).

Text-based chat was often described as "slow". Yet despite this, as discussions began to focus on specific aspects of the project, "it just got faster" (5b1 interview). Whether this was due to familiarity with the technology, the mode of communication or the focus of the task is unclear.

In a reflection by one participant it was noted that although they mostly used text-based tools to communicate "there are no social or body cues (non-verbal information) to aid understanding. This sometimes can lead to misunderstandings." (3a1 reflection). However, several other participants described the avatars as supporting communication, in the code avatar \& communication, by "walking over to an area that kind of indicated what you might be talking about" (2a1 interview). Another participant stated that "it helped that you were looking at somebody face to face, you kind of knew if they had scurried off to the corner that they were sick of listening to you, or you know, that they wanted to do their own thing, so, it was easier to communicate in that sense. I suppose you had a feeling that there was somebody else there." (5b1 interview). Others described the avatars as supporting group work by providing a focal point, removing distractions and inhibitions, allowing groups to communicate more easily.

\subsubsection{Collaboration}

When asked about their collaborative work, learners described working with their partner in Second Life and on their own, depending on personal time commitments. As a result, there was evidence of both synchronous and asynchronous collaboration within groups.

Learners emphasized the importance of discussion for the clear division of tasks and the creation of roles, when preparing to work in Second Life at different times. When working together learners would either: work on individual set tasks, asking their partner for feedback and support; or work on one task together. However, in the latter situation learners described the inability to observe what their partner was doing in S4SL as limiting collaboration and opportunities for peerlearning. As noted in one reflection: "However, in terms of working as a team to create this project SL has had its limitations - we both were unable to show the other what we were doing in terms of sharing the code/actions in real time - there is no shared access to each other's desktops and we see this as a major limitation in terms of active participation - one at times is going to be an observer but yet not being able to observe what is going on behind the scene." Despite this limitation, in their reflections many groups described working on programs together.

Collaboration tended to focus on unfamiliar tasks, with both experienced and novice programmers supporting each other: "there were absolute cases where I just couldn't see why something wasn't working, and erm, then $5 b 1$ would have suggested something that would never have occurred to me, and it was actually quite simple, you know that kind of a way? Where sometimes you're thinking, you're just thinking down the wrong route, and somebody else, you know, can drag you back on it." (5b2 interview).

Except for the initial workshop and preparation of their in-class presentation, many groups met exclusively online. For some, the need for face-to-face collaboration arose from difficulty with the communication tools; the permissions system; or the inability to observe their partner's desktop. In the code avatar supports collaboration, avatars were described by some participants as supporting collaboration at a distance, providing an opportunity to observe: "by watching each other and seeing what you were doing ... flying up together to get a perspective of the area, to say, oh here, let's put the house there, let's put the fountain there ... And it was getting the perspective together, you know, from the same angle." (2a1 interview).

\subsection{Learning environment and design}

'Learning environment and design' draws attention to the relationship between the virtual environment and the artefacts created. In Fig. 7 they are represented as two categories, however they are not efficient categories as described by Merriam (1998) as they are strongly related and both have the sub-category of 'Public'. As a result, they have been combined into one category, to be discussed in combination and separately.

\subsubsection{Learning environment}

The learning environment refers to the general features of the technology such as the representation of three-dimensional space and avatars, as well as the purpose-built platforms for each pair.

Many participants described the three-dimensional environment of Second Life as providing them with a sense of being in a physical environment: "because it's 3-D, its physical, it's got surroundings to it." (2b1 interview). Avatars were also described as mediating the sense of a physical environment, however for some participants this was not the case: "I do prefer to directly experience the objects rather than through an avatar. The physical contact is very important for me and this is something I missed." (3a1 Reflection). These participants also described feeling uncomfortable identifying themselves and others through avatars. However, the majority of interviewees described the avatar as essential to the learning experience: "If there was no avatar and the two of you logged in ... It would lessen the experience." (1a2 interview).

Avatars supported a sense of immersion within the Second Life environment as well as co-presence with other learners. The sense of co-presence was also supported by the public nature of the learning environment which allowed them to enter other groups' spaces, discussed in the sub-category 'Public' (4.2.3). "This was you in the same space online. And that distinction of online disappeared. There is somebody here. They are walking up, they are walking in, they are flying, you see them flying over and you know who they are because something has popped up where you just know who they are. So, it did feel rude not to engage in some form of conversation." (2b1 interview). 


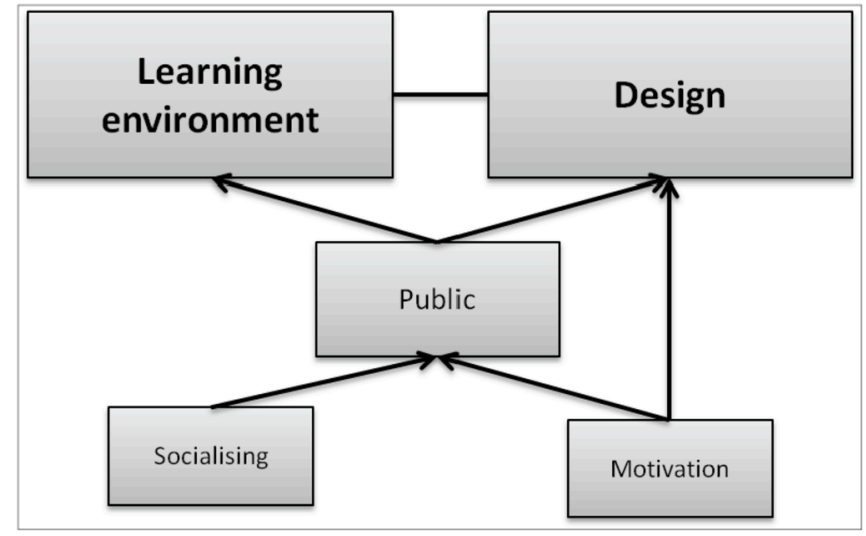

Fig. 7. Representation of 'Learning environment and design' category.

Although all participants had taken part in short activities in Second Life earlier in the course, some described their interaction with SLurtles as resulting in their first experience of immersion in which technology became 'invisible': "the Second Life Saturday and the avatar and sitting on benches and the lecture and the voice that was my first immersive experience of the whole thing. And the oddness of it was very distracting. And what was interesting about the SLurtles and engaging with your own scripting control of something was, you're suddenly focused on something inside the environment, where the environment now becomes, goes into your peripheral sort of consciousness. ..., that was the moment, where the experience of acting in an avatar's virtual presence I sort of, I got the real deal." (1a2 interview).

While each groups' artefacts utilised the almost infinite height of the learning spaces, few identified it as a particular advantage or disadvantage in the design process. By comparison, in the code influence of presentation space, the size of the construction space did influence constructions: "the space was very big, and we did feel like, you feel like you want to fill it, and you can see we put that wall there, erm, just to get the sense of it being filled" (2a1 interview).

\subsubsection{Design}

The design process for the installation began with exploring and generating initial ideas, followed by development, planning and construction. Most groups described returning to each of these stages in the design process several times over the four weeks.

Exploring how to use SLurtles and what could be created with them helped learners to generate ideas. This exploration was supported by the ease with which learners were able to engage in construction through the SLurtles. To support the planning and construction process two groups described using paper and pen to map out their ideas.

The sense of inhabiting the learning space via an avatar was described by several participants as supporting the development of initial ideas, construction and development of the artefacts created by the groups. For example, in one reflection a participant noted: "It was within the virtual space that we formulated the decision of what to make, something we had struggled to achieve in the offline world. I wondered if being immersed in the virtual space, while contemplating the possibilities, had helped in arriving at this decision. We were now immersed in the space, getting a sense of its scale and depth, and watching other installations beginning to take shape. I think this helped clarify a few ideas we had brought to the space to discuss and brainstorm. In a manner of speaking, being immersed in the space helped us realise the possibilities." (4a1 Reflection).

Despite experiencing some frustration with coding, learners expressed an often surprising sense of achievement in their final artefact: "the sense of achievement at finishing the project is something I underestimated" (3a2 reflection). This achievement was attributed to various forms of motivating factors, discussed in the sub-category of 'Motivation' (4.2.4), as well as the ease with which they could use the
SLurtles: "definitely will use it again because it was so great you could actually build stuff like that" (1a1 interview). Although one participant expressed disappointment as "It didn't look as perfect as I wanted it to" (1a1 interview), she also stated: "I think it worked out fantastically".

\subsubsection{Public}

'Public' is a sub-category of importance to both the learning environment and design. While the island used for the learning experience was a private space to address ethical concerns previously discussed, each group's platform was accessible to every member of the class and this influenced both the learning experience and the final designs. For example, several participants stated that they got their ideas for certain aspects of their design from other groups. This is strongly linked to the sub-category of 'Motivation' which influenced the design of artefacts.

Learners were aware that their virtual learning space was a shared space, as noted in one reflection: "We were immersed in our own learning and construction, while surrounded by the progress of the learning and construction of others." (5b2 reflection). However, one learner expressed a desire not to see what others were creating. The edge of each space was marked by a semi-transparent wall, designed to prevent avatars falling off their platform whilst allowing learners to view other groups' spaces. Yet he described wanting to be able to block his view of other groups' spaces: "Partly, I put the poster boards up to block out, as I call it, Vegas, that's next door. It's just so busy with so much going on I felt I had to block it out". But most participants described being able to see into other groups' spaces an important part of the learning experience: "made complete and absolute sense that you would have transparent walls because you were building something in a constructionist environment, where, because it's public there is more emphasis on people to actually do it and make it good" (2b1 interview).

Most groups were keen to have other groups visit and explore their artefacts. For some this even became an important design consideration: "trying to put notes or boards at the back for people to see to give them ideas of what to play, to help them start off, if they never played the piano before" (3a2 interview). In addition, by sharing their constructions groups gained feedback on their artefacts from others, while some groups were influenced to further develop their artefacts after they had explored other groups' artefacts.

Within the walls of each platform a gap provided an entry/exit point for avatars travelling to the platform by foot. The design of several groups' artefacts incorporated this gap, placing a scripted door or 'welcome mat'. However some participants, in both chat logs and interviews, described feeling that this change to the original design of the learning space was detrimental to the otherwise public nature of the learning experience: "we noticed some doors going up on the spaces, erm, and we thought that was quite, I don't know, well, a bit odd to be honest ... there almost seemed to be some sort of guardedness about individual projects, and so doors started to appear across some of the entrances to some of the spaces, and erm, I thought that was funny, I thought it sent out a message" (5b2 interview).

Represented as an avatar within the learning environment, learners experienced a sense of presence within a public space. Several participants stated that at times they wished they could be invisible in the learning environment: "at times when you're kind of under pressure it didn't, it was less convenient that you couldn't make yourself invisible, just to kind of say I'm not here." (2a1 interview). Despite this, learners described the presence of avatars as supporting the learning experience. Seeing other avatars in the same space reduced perceptions of loneliness and supported collaboration between groups: "it helped not knowing you were the only one, you weren't the only one in there. Do you know? And I suppose like you'd see other people there and you could ask other people for help or advice or how to do this or how do you do that? Or vice versa. So it was great, that kind of way" (3a2 interview).

\subsubsection{Motivation}

Knowing that other learners could see and interact with their 
artefacts throughout the four weeks was an extrinsic motivator which influenced the design process including idea development and construction of the artefact, as noted in one group reflection: "A piano will provide an engaging and fun experience for the user through its interactivity." (3a group reflection). One of these learners participating in the interview notes that on seeing other groups' installation spaces they decided to add objects to fill theirs, specifically poster boards with simple pieces of music that could be played. Thus, while the overall idea or theme for their space may not have changed, components of the design did, suggesting that the design developed over time.

However, although they had nearly completed before the end of the four weeks, one group wanted to be able to show the class something they would not have seen prior to their class presentation: "I don't want to have it completely done until the day before the presentation because I wouldn't want them to go through it." (1a1 interview).

Due to the public nature of the learning environment, learners described "looking at other people's work, and you realised, oh, you can do this as well, you know, or other people have used that so let's have a go" (5b1 interview). This realization influenced the design of several artefacts; yet there was no evidence in the artefacts of simple copying of programs as indicated by the variety of trees created across groups in Fig. 8.

Several participants described in their reflections and interviews, feeling motivated by a sense of fun and excitement. As one participant noted in their reflection: "A sense of excitement was definitely a motivating force" (5b2 reflection), while their partner stated in their interview "it didn't actually feel like an assignment at times, you kind of felt guilty that you were having, doing this because it felt like fun" (5b1 interview).

With a sense of fun came challenges. While several participants described the challenges and sense of satisfaction in programming the SLurtles, one described being challenged by their partner through the construction process: "we enjoyed kind of pushing, you know, kind of pushing each other on every kind of step in it". These challenges were considered valuable and encouraged learners to further develop their existing ideas: "so that was a good thing then, that it did feel like something that was worth doing because it was fun and it was interesting. So, erm, I think because of that our ideas did develop and we were willing to try new things, whereas if it was something that we found was a chore to do we just would have left it, and said $\mathrm{OK}$, we've enough done to tick the boxes and that's it." (5b1 interview).

\subsubsection{Socialising}

The learning environment provided opportunities for learners to

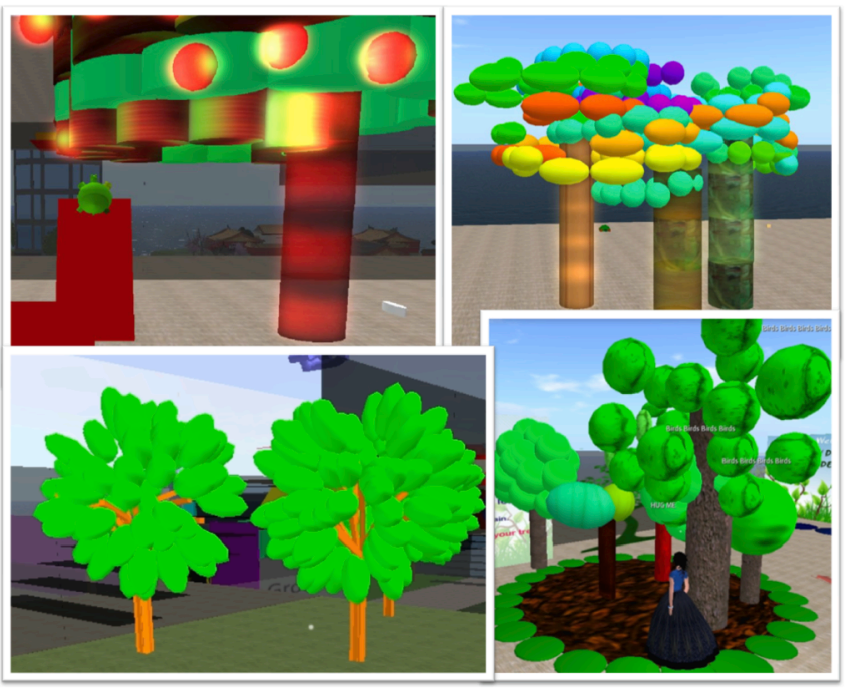

Fig. 8. A variety of trees found in different installations, created by different participants using SLurtles. socialize. This typically occurred when learners visited other groups' platforms. Whilst this was described as supporting the learning experience, it added pressure for some and others avoided it. This subcategory focuses on the sense of co-presence and the code etiquette, which was a particularly common code across interviews.

Avatars supported work related communication within the group. Across interviews avatars were also described as supporting informal communication between participants. Only one participant described not communicating with avatars other than his partner: "I deliberately stayed away." (1b1 interview). For most participants the avatars supported and encouraged social communication: "they popped up and then I'd go over to them, just quick chitchat, how you getting on, kind of." (2b1 interview).

It is in this informal communication setting in which avatar presence in a space evoked a need to follow a perceived etiquette. Some participants were frustrated by the "rudeness" of others, whilst others did not wish to appear rude: "Erm, I, because people type slow. And, you feel like you kind of have to sit there, and kind of pay attention" (2a1 interview).

Social interaction, whilst alleviating a sense of loneliness, could add pressure "see I did find it frustrating, I was saying I was lonely over here but a lot of people kept dropping in to visit, and you're kind of trying to get things done, and they would mostly just use the text tool because it was, you know, it was good and it was nice and it was fun, and I wish I had more time to chat, but sometimes you felt rude, like you couldn't ignore the text because it was there, so you had to have a chat, but you'd be awful busy and kind of feel like, go away." (2a1 interview).

\subsection{Learning}

The final category is 'Learning' (Fig. 9). Over the course of the four weeks there were two re-occurring learning episodes identified by the participants: learning for the learning experience; and learning through the learning experience. Within this category how learners gained their new knowledge and understanding is also explored.

\subsubsection{Learning in order to participate}

In the first type of learning episode, learning focused on Second Life specific skills necessary to engage in the learning experience. These included how to control an avatar's movement and how to use the camera controls, which were identified as initial barriers to engagement. However other essential skills were not identified as barriers. These included learning how to program with S4SL, how to create a script in Second Life and import the S4SL script. As described by one participant these were the "mechanics" of using SLurtles.

As they engaged in the learning activity these skills became more familiar as did the virtual environment: "I actually found it quite easy to forget that you were actually, you know, in the zone of a virtual world" (5b2 interview). It is interesting to note that while many skills became familiar some learners expressed ongoing frustration with transferring

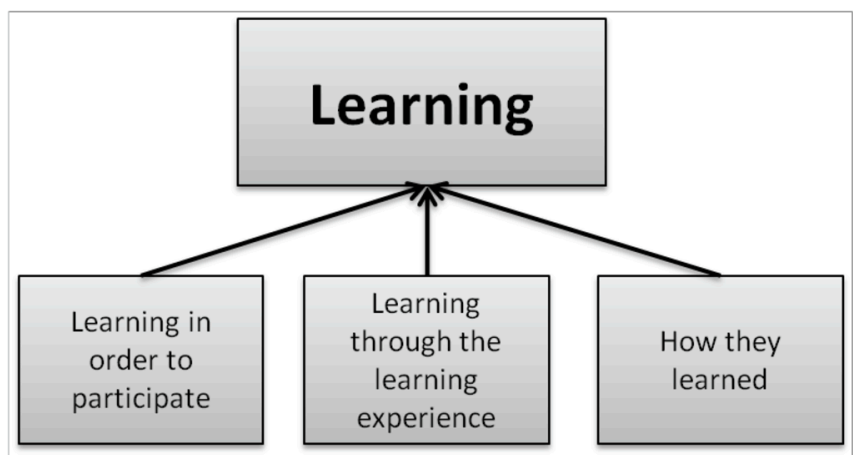

Fig. 9. Representation of 'Learning' category. 
scripts from S4SL to Second Life and back again. This resulted in S4SL being reinstalled as a temporary fix. As a result, it may be suggested that for these learners the software did not become invisible.

\subsubsection{Learning through the experience}

Having acquired some basic skills during the initial face-to-face workshop sessions, several participants described learning about the potential of S4SL and SLurtles by engaging in the construction of their artefact, as shown in this reflection comment: "I believe that I learned much more about the Scratch programe in the first hour of building the first section of our installation than I did during the entire in college lab/lecture sessions. This is not a criticism of the learning experience delivered during the in college sessions ... Rather, it is an observation into the level and depth of learning that seemed to occur when applying it to a vision" (5b2 reflection). Learners described beginning the learning activity (after the face-toface workshop) by exploring what SLurtles could do.

Learning was typically incremental over the four weeks and illustrated in the developing installations, some which were made and remade several times. By engaging with SLurtles to create an artefact, learners identified that they had learnt about: reflection and its role in problem solving; programming concepts and processes; 3D graphics; advanced mathematics; themselves as learners, collaborators and teachers; collaborating at distance; and pedagogies introduced on the course, in particular constructionism: "the greatest learning experience was the learning in relation to the process; by being an active participant in the process, while exploring the process, and subsequently reflecting upon the entire experience." (5b2 reflection).

They also learned about the artefacts they were creating. As noted in reflections, some groups created unfamiliar objects which they learned about through the construction process: "Regarding the piano both of us would not have been very familiar with the piano and thus learned about the different keys and the positioning of those keys. We even learned to play some simple tunes." (3a group reflection).

\subsubsection{How they learned}

As noted in interviews, the task and having a partner were the two main aspects of the learning experience that supported learning: "you are there to collaborate on a very challenging operation, which is outside of your comfort zone and in doing that you're going to learn extraordinary things about yourself. By working with other people that will give you a completely new perspective on the task itself. And you yourself, and perhaps learning itself." (1b1 interview).

Those that worked with a partner who had some programming experience described their partner as supporting their learning. For example, having "somebody there with more knowledge than myself, I suppose to kind of scaffold the learning process" (3a1 interview) was noted by several participants as an important aspect of the learning experience.

In groups with no experienced programmer, learners described their experience as "better because we were both on equal, equal ground, starting off" (5b1 reflection). As a result, they described learning together. However as noted in 'Imbalance' (4.1.1), where there was a knowledge imbalance, groups needed to identify the imbalance before they were able to learn from or with each other.

Visiting other groups' learning spaces and interacting with avatars outside their own group was a valuable learning opportunity identified by several participants. Thus, learners were able to explore alternative ideas and were motivated to develop their own artefacts. In general the learning environment was described as supporting learning, as illustrated in this reflection: "I felt completely immersed in the virtual world and as a result I constructed knowledge based on my interactions and experiences in the virtual world (conversing with other avatars: exchanging knowledge, interacting with SLurtles and Prims)" (3a1 Reflection).

By engaging with SLurtles and engaging in reflection, participants learned programming concepts and processes. In interviews and reflections we find that references coded at exploration were also often coded at play or fun, whilst testing was linked to frustration and reflection. It is interesting to note that exploring, testing and extending understanding were also closely linked to learners describing the movement of SLurtles, as shown in the following reflection: "The fact that I could get immediate feedback from watching the actions of the SLurtle allowed me to evaluate what the script was doing in comparison to what I wanted to happen. I found this visual feedback allowed for an accelerated understanding of what was happening within the script than if I had to think in the abstract as to what was happening." (5b1 reflection).

One group created a bowling alley as part of their artefact. When clicked a ball would roll towards the pins, apparently knocking them over at which point a 'Strike!' message would appear. As described by one member of the group this artefact required a lot of problem solving: "To actually figure all this out because it was, like, a fair bit of problem solving on it in terms of, like, one we couldn't figure out why the ball would not go down the full length ... and then we tried, erm, we tried commands with the pins, ... but that wouldn't work because the collide was with the pins and it wasn't with the ball. So that's why what we had to do was to simulate the actual ball hitting the pins. And you wouldn't notice when you're standing here, that it's actually just timed, erm, so when the ball would roughly be where the pins were, then they would knock over" (5b2 interview).

While some learners identified the use of reflection early on in their problem solving, for others it was a strategy they learnt to use over time: "I wouldn't reflect at all, whereas I think $3 a 1$ would be a much more a reflective person, and I think I got that from her. And then kind of reflected more myself." (3b2 reflection). Partners were also influential on learner's approaches to problem solving. Learners described their partner as supporting their thinking process when working on a problem together: "sometimes you're thinking, you're just thinking down the wrong route, and somebody else, you know, can drag you back on it" (5b2 interview).

This feedback also helped learners to identify characteristics of the SLurtle they were previously unaware of: "it comes out the middle, so he draws, we wanted to make it 0.1 wide. But he draws 0.05 on this side and 0.05 on that side" ( $3 \mathrm{a} 2$ interview). This resulted in several groups using alternative approaches such as pen and paper to plan their designs and programmes rather than rely on abstract conceptualisation from which to plan the programme: "I did the math in my head and talked through it with $3 a 1$ but we never got it right. We were actively experimenting but getting it wrong every time. Finally I took out two pens and a piece of graph paper and $3 a 1$ did the same." (3a2 interview).

While a number of participants noted using a trial and error approach, several learners identified that over the duration of the learning experience their approaches to problem solving changed, as described in one interview: "Maybe I do it in a different way, but this taking a step back, looking at things how they work, how ... and then thinking, what will we do now as a result of that and why didn't it work, or why did it work and that kind a way of thinking, that methodology of thinking is very good and it was effective" (3a2 interview).

There were many observational notes made about the appearance of initial constructions, which were either completely removed or added to throughout the learning experience. Learners used SLurtles to build and rebuild artefacts as they explored and tested their understanding, and this was identified by several participants as an important feature: "being able to erase and start all over again is great." (5a1 Refection). Participants used SLurtles to construct objects, however to remove them they used the Second Life tools, as illustrated in this excerpt from a chat log: "now to delete my mess ... i presume i can select all the blocks using the build button? (sic)". As objects were non-physical they could be created at any height and would stay in that position: "at one stage it became easier to put the SLurtle up a height and then execute the commands and look at them from there." (5b2 interview).

Some, although aware that the objects were intangible, viewed the learning environment and objects as physical: "it's not like a website, because it's 3-D, its physical, it's got surroundings to it" (2b1 interview). However, others described this experience as mediated through their avatar and as a result they were not as close to the objects as they would 
be in the physical world: "I also recognise that my learning is stronger when I get to experiment with building objects in the real world and the SL has provided me (to some extent) with this opportunity. I do prefer to directly experience the objects rather than through an avatar." (3a1 Reflection).

\section{Discussion}

To examine constructionism in action in virtual worlds, this discussion of these findings is separated into three sections. The first discusses the findings through the lens of constructionist pedagogy and is followed by an examination of the findings in relation to the perceived educational affordances of virtual worlds. Finally, the proposed alignment of pedagogical theory and technical affordances is discussed. For clarity, each pedagogic feature or perceived educational affordance is highlighted in bold.

\subsection{Constructionism in action}

All groups created personally meaningful artefacts. This was facilitated by SLurtles and the design of the learning experience in which learners were given an open task which required them to create an interactive installation using SLurtles. This provided learners with a wide scope as to what they could create and allowed them to pursue their own interests, providing them with an opportunity to create personally meaningful artefacts, whether a piano, bowling alley or enchanted forest.

Through the development of their installations, learners engaged in multiple iterations of design, creation, destruction and development as they actively explored, tested and extended their understanding of programming, mathematics and what the SLurtles were capable of. Activities which led to exploring, testing and eventual extending of understanding were often prompted by the need to solve a problem which appeared unique to the individual or pair, although others may have encountered the same problems.

The main task was purposely designed to provide learners with opportunities to program and this was often the focus of learners' problem solving activities. There was evidence across all data sets that all learners engaged in programming with S4SL in order to create SLurtle blocks and add interactivity.

Through the design of the learning environment, all learners could visit the artefacts of others, thus sharing artefacts that had been created. While a few learners did not wish to visit other groups nor for others to visit them, most learners took the opportunity to explore the artefacts created by other groups at various points during the learning experience. Thus learners were also involved in sharing both complete and incomplete artefacts. The latter provided opportunity for feedback, requesting help and observing the process of construction.

While the SLurtle constructions were easily shared between groups, the programs implemented by SLurtles to create the artefacts were inaccessible to those who had not created them. In addition, the programs which made the artefacts interactive were inaccessible due to the permissions system. Learners were also unable to share in the development of programs in S4SL. Thus the SLurtle constructed artefacts were easily shared but not the programs.

Bricolage refers to the development of an artefact over time (Papert, 1991) and was evident across data sets, particularly observations which captured the early development of constructions. As previously described, groups developed their installations throughout the 4 weeks as their knowledge and understanding of programming developed. Some initially focused on a 'centerpiece' and then decided they needed to fill their remaining space, as described in the 'Learning environment and design' category, while others were influenced by the artefacts created around them. Although most groups described their artefacts as developing and changing over the four weeks, a few stated that their original ideas did not change throughout the process.

In situ refers to the location that learning takes place. Most learners described in their interviews or reflections undertaking problem solving and developing their understanding within the virtual rather than physical world. However, some described 'ending up' using pen and paper to solve some programming problems. The virtual world was also the place where ideas emerged and were developed, with learners influenced by the creations of others appearing around them. The public and shared nature of the space appears to have facilitated this and is discussed further below.

Papert (1980s) describes wishing the computer to be 'invisible' during learning experiences, much like a pencil is invisible when writing, "The computer becomes just an instrument". This 'invisible' technology means that the learner does not need to focus on how to use the software or input devices and instead focuses on the learning content. Although the researcher-generated codes demonstrate that learners began by learning the skills required to use S4SL and Second Life, as they engaged in the learning activity these skills became more familiar as did the virtual environment and quickly became like the pen or paper referred to by Papert. In this way the technology became invisible. While many skills became familiar some learners expressed ongoing frustration with transferring scripts from S4SL to Second Life and back again. As a result, it may be suggested that for these learners the software did not become invisible.

Collaborating on constructions was self-reported by the learners and developed into the in vivo code collaboration. Again, the task was designed to require pairs of learners to work together, and therefore it could be considered as unsurprising that 'group work' emerged as a category. In their reflections each group reported collaborating on the construction of their artefact and as shown in the sub-category 'collaboration' there is evidence of collaboration taking place during the learning experience both within and between groups. However, the sub-category 'imbalance' provides evidence that such collaboration may not have occurred throughout the learning experience, yet once an imbalance was addressed by a group they were able to collaborate on constructions.

As artefacts were constructed in a publicly accessible space there was an opportunity to discuss constructions and to share code. Importantly, this occurred both within and between groups, as noted in one interview. While learners shared and discussed programs, there was no evidence of learners simply copying the code created by others, as highlighted in the sub-category 'motivation'.

Although learners recognized that artefacts were shareable with others in their class they were also aware of the barriers to sharing scripts and SLurtle blocks within their group. The Second Life permission system was identified as a barrier to the learning experience, limiting the sharing of and collaboration on scripts, although many learners found work-arounds.

\subsection{Perceived educational affordances of virtual worlds}

The perceived educational affordance of the creation of persistent objects was leveraged throughout the learning experience. To aid discussion, this perceived educational affordance is broken down into its three constituent parts: construction, programming and persistence (Table 1). Across the installations that were constructed there were many examples of learners using S4SL to program both SLurtles to build and program the installations to be interactive. Although the task required learners to use S4SL, it is interesting to note that there was no evidence of any participant using Second Life's programming environment, whether experienced programmer or not. Persistence was an important perceived educational affordance as, together with the public nature of the learning environment, it allowed learners to watch "other installations beginning to take shape" over time and without the person constructing the artefact being online. It also provided an opportunity for learners to gain feedback from others and allowed learners to contribute to the construction of their artefact when their partner was offline. 
Second Life afforded flexibility in terms of both time and location of learners' engagement. Chat logs demonstrate the variety of times of day that learners logged into Second Life. Interviews show that learners were able to collaborate at distance from their homes or in a face-to-face setting depending on their requirements, synchronously or asynchronously.

Learners identified a sense of presence in the learning environment and co-presence with others through embodiment in their avatars, as discussed in the category 'learning environment and design'. The subcategory of 'socialising' also highlights that the three-dimensional environment, avatars and communication tools also supported socialising between groups within a public environment. This sense of an embodied social presence is also clear in those learners who disliked being visible to others, perceiving it to be a limitation of the environment.

Five participants explicitly stated in reflections or interviews that they felt immersed in both Second Life and the learning experience. There was no evidence to suggest that any of the other participants did not. Learners who identified being immersed in the Second Life environment identified the three-dimensional landscape, avatars and communication tools as supporting the sense of immersion. Participants identified several features of immersion such as not noticing the passage of time as they engaged in programming the SLurtles. As noted in one reflection: "time doesn't seem to exist there and one can get so immersed in the experience that one loses track of time". Another feature of immersion identified in one reflection was the learner losing awareness of the computer interface: "Looking back, its quite incredible to think that the vista for all this activity was a very narrow laptop screen ... For the large part it was very easy to be fully immersed in the experience. It was easy to forget just how narrow this vista was, and even easier to feel absorbed by its seemingly eternal depth."

There was evidence of both collaboration and learning taking place during the learning experience. However, there was much less evidence of collaborative learning. Where a programmer and non-programmer were paired together, learning tended to be one-way and this could be constrained by the communication tools available in Second Life. Those that described learning together often described the inability to observe the other person's screen as limiting collaborative learning.

\subsection{Alignment of constructionism and virtual worlds in action}

As demonstrated, learners engaged in each of the features of constructionist learning over the course of the learning experience and the perceived educational affordances were found to support learners' engagement. However, the findings do not identify any causal relationships between the perceived educational affordances of the technology and the features of the pedagogy. That is to say, the technology and pedagogy alone do nothing without the learning designer, instructor and learner.

This section considers the proposed alignment of the features of constructionism and the perceived educational affordances of virtual worlds as shown in Table 1. These are discussed under the headings of the features of constructionism. Avatars were found to be a cross-category theme appearing to influence several aspects of the constructionist learning experience and so are discussed here and returned to in the conclusion.

\subsubsection{Construct personally meaningful artefacts to actively explore, test} and extend understanding

The findings show that the learning experience provided all learners with an opportunity to construct personally meaningful artefacts and through their construction learners were able to explore, test and extend their understanding of programming and mathematics. While SLurtles enabled learners to construct their artefacts as well as develop their understanding of programming and mathematics, there were other barriers to the construction process that emerged.

As discussed, some generic Second Life skills and tools were identified as limiting learners' initial engagement with SLurtles. While avatar movement was an initial barrier to engagement identified by some, avatars were found to support communication in both group and social settings. Camera controls were also found by some to be a barrier to the construction process. However, those comfortable with their avatar, described their avatar as an essential element of the learning experience, particularly in providing them with an opportunity to observe their partner and construct personally meaningful artefacts.

\subsubsection{Opportunity to program}

One of the aims of the learning experience was for learners to gain an experience of programming. Although learners were not taught any specific programming concepts there was evidence from artefacts and interviews of learners using and, in their own words, "learning" several programming concepts. Through engaging in the construction of their artefacts via SLurtles, learners were provided with not only an opportunity to program but also an extrinsic need to engage in programming.

S4SL provided learners with a low-floor tool for programming and while it does not provide every function of the LSL language, those learners with experience of programming were able to create complex programs through the use of variables. Although learners described S4SL as easy to use, several found the transfer of scripts from S4SL to SLurtles to be an initial barrier. Over time this barrier was overcome by all learners through their continued engagement in the construction of their artefacts with SLurtles. While this barrier may have the potential to prevent learners from engaging in programming and the construction of personally meaningful artefacts, this case study suggests that this barrier is temporary.

Constructionist learning environments are designed to enhance the most important features whilst removing those that might distract the learner by "muddying" the outcome (Edwards, 1998). While there was no evidence to suggest that the transfer of scripts from S4SL to SLurtles "muddied" the outcomes, this does not mean that it did not happen. By comparison there was evidence that this barrier initially distracted learners, requiring them to focus and learn the process of transferring the scripts, suggesting that the technology was not 'invisible' from the start of the experience. As such this barrier may require further research on its impact on learners' engagement as well as future technical development.

\subsection{3. 'Invisible' technology}

Of the three levels of immersion identified by Brown and Cairns (2004, p. pp1279), there was evidence of some learners experiencing the third level, total immersion, characterized by the learner being no longer aware of the computer interface. As such the technology became 'invisible'.

Most learners experienced the second level of immersion, engrossment, in which the controls become 'invisible', in other words the learner does not need to think about how to use them in order to use them. However as noted above the transfer of scripts and general virtual world skills such as walking, were an initial barrier for some learners which limited their initial engagement in the learning experience. Engagement is the first level of immersion identified by Brown and Cairns (2004, p. pp1279) in which participants have overcome these initial barriers and are able to engage in the game or, in the case of this study, the learning experience. Thus, not all learners experienced immersion throughout the learning experience and many experienced different levels of immersion at different times.

It is also possible that by moving between S4SL and Second Life the sense of immersion may have been reduced. Faiola and Smyslova (2009) note that a sense of presence within virtual worlds supports immersion. Removing the learner from the virtual world in which they are embodied as an avatar to the stand-alone application S4SL in which there is no embodiment or co-presence, may have limited the level and length of immersion learners experienced and reduced the sense of learning in-situ. Thus, while learners experienced immersion whilst in- 
world, supporting the constructionist notion of 'invisible' technology, by leaving Second Life in order to program the SLurtles, the sense of immersion and an 'invisible' technology may be lost.

\subsubsection{Shareable artefact}

Within the category 'learning environment and design' there was evidence to show that learners were aware that the artefacts they created were shareable both during and following their construction. As anticipated this was supported by the persistent nature of the environment, allowing others to visit artefacts when those that had constructed them were offline, however the public nature of the learning environment was also important. When online, the public nature of the learning environment enabled learners to visit each other's learning spaces to observe and discuss the artefacts, especially their development. The public nature of the environment also supported learners' social interactions within the wider group.

All constructions could easily be shared at all stages of the learning experience as each groups' space had a combination of semi-transparent low walls and the access system was used to provide all members of the class access to each learning space. The access system was also used to prevent non-members from accessing the island. However, in a different learning context it may be suitable to provide open access to nonmembers. Alternatively, the access system could be used to prevent member avatars from visiting the constructions of others.

Some participants expressed a desire to have a private area where they could test their programs. While private learning spaces, in combination with opaque high walls and roofs, would allow learners to share only their completed artefacts, this would prevent them and others from engaging in dialogue about the constructions during the construction process. Thus, opportunities for groups to learn from one another during the learning experience would be greatly limited.

While persistence is necessary for artefacts to be shared when their creators are not online, it appears that the access controls, which afford learners either public or private learning spaces, are also important. While Dickey (2011) identifies security as a perceived educational affordance, related to access controls, the findings of this study suggest that it is the public or private nature of the environment rather than security which was important to learners. As such, 'public or private learning environments' is also considered to be a perceived educational affordance of this feature of the technology. Therefore, this perceived educational affordance needs to be leveraged to provide public learning environments to support the sharing of artefacts during constructionist learning experiences in virtual worlds.

\subsubsection{Bricolage}

Papert (1991) uses the term bricolage to refer to the development of an artefact over time. Rather than following a pre-determined design, the design of the artefact develops during the construction process. Both construction tools and flexibility afforded by virtual worlds supported bricolage, allowing learners to build and rebuild their artefacts. Thus, learners were able to develop their artefacts from their initial ideas as they gained a greater understanding of programming, the potential of construction with SLurtles and their own ability.

In order to engage in bricolage, learners need to engage over a period of time. The virtual world allowed learners not only to engage over a period of time but at a time and from a location that suited them.

\subsubsection{In-situ}

The majority of learners described participating in the learning experience and engaging with other learners 'in-world'. This was clearly supported by the embodied social presence afforded by the learners' avatars. 'Avatar' was a cross-category theme, particularly strong in 'group work', 'learning environment and design'. Together with avatars, the 3D environment and communication tools provided learners with a sense of presence in the environment and co-presence with others. They supported the construction and sharing of artefacts, enabled socialising and supported peer-learning.

Embodied social presence supported learners in participating in the learning experience within the virtual world. Thus, their learning could be defined within a certain context, described by Ackerman (2004) as in-situ. Additionally, learners expressed gaining knowledge which could be transferred to other learning contexts.

While many learners engaged in the learning experience within the virtual world, others felt the need to meet face-to-face or to problem solve using pen and paper. Thus they engaged in aspects of the learning experience outside of the virtual world. Therefore, the learning context is extended outside of the virtual world and in these contexts is not supported by the perceived educational affordance of embodied social presence.

The use of an avatar appears to have influenced many aspects of the learners' experience of constructionist learning in the virtual world. The avatar appears to have supported learners' sense of embodied social presence and immersion within the learning environment, allowing them to visit, share and discuss constructions in-situ. They supported a limited observation of partners and enhanced the sense of being in a public space. Although a few participants described identifying themselves through an avatar as uncomfortable, others found it liberating, which resonates with the wider literature on virtual worlds in education. Those comfortable with their avatar, described their avatar as an essential element of the learning experience, particularly in providing them with an opportunity to observe their partners and construct personally meaningful artefacts. While the embodied social presence and engagement in the learning experience was found to support collaboration, it did not necessarily support collaborative learning which was also limited by other factors.

As Taylor (2002) notes, it is impossible to forget that others are present in a virtual world and similarly it is impossible to become invisible in Second Life. Thus the avatar provides an outward signal of being present in the virtual world. Many learners described this as an advantage over typical assignments on the course, providing opportunities to learn with and from their peers. Yet others found that the appearance of an avatar could be distracting, invoking social norms that they felt obliged to follow, and at the extreme it had the potential to limit learning.

\subsubsection{Collaborating on constructions}

Avatars, communication tools and the 3D environment were found to afford learners an embodied social presence within the virtual world. This embodied social presence and engagement in the learning experience supported collaboration on constructions. However, there was limited evidence of collaborative learning which was theoretically aligned to collaborating on constructions and anticipated to support this feature of the pedagogy.

Gamage, Tretiakov, and Crump (2011) link the perceived educational affordance of co-presence to Dalgarno and Lee's (2010) collaborative learning in virtual worlds. However, it was also noted that collaborative learning is a form of activity, in which features such as communication tools and avatars, in combination with an activity, afford collaborative learning.

There was substantial evidence of learners engaging in the learning activity, using communication tools and avatars. This would suggest that while learners both engaged in the learning activity and experienced an embodied social presence within the virtual world through the use of avatars and communication tools in the 3D environment, these did not lead to collaborative learning. Yet they did support the collaborative construction, discussion and sharing of artefacts. Thus while embodied social presence and engagement in the learning experience support collaboration they do not necessarily support collaborative learning. This may be due to the barriers identified by the learners or the design of the learning experience.

Collaborative learning was limited by imbalances within groups. Second Life's communication tools were identified as a barrier by some 
learners, however an increase in communication and discussion was needed to address group imbalances. These imbalances and barriers may have been the reason why some groups reported a need to meet face-to-face or used Skype as the preferred medium for communication. Although avatars supported learners in the observation of their partners, they were unable to observe their actions in S4SL and this was also found to limit collaborative learning. This was further hindered by the permission system which was a barrier to learners sharing their programs within Second Life. It is likely that skill-based barriers to collaborative learning may also have been barriers to immersion, limiting engagement in the learning experience.

Although the findings suggest that collaborative learning was limited there was evidence of all three forms of Resnick's (1996) distributed constructionism: discussing constructions; sharing constructions; and collaborating on constructions. The proposed alignment between the perceived educational affordance of collaborative learning and collaborating on constructions. While the embodied social presence, persistence and public nature of the learning environment were found to support the discussion and sharing of constructions, there is little evidence in the findings to support the alignment of collaborative learning and collaboration on constructions. Thus this aspect of the alignment between pedagogy and technology requires further development.

\section{Conclusion}

Constructionist theory posits that learning is most effective when learners engage in the construction of personally meaningful and shareable artefacts as they actively explore, test and extend their understanding (Papert, 1991). Artefacts develop in-situ over time through a process of bricolage and the construction process is facilitated through the use of 'invisible' technology (Papert, 1980s). Programming is also a central aspect of most constructionist learning experiences (Hoyles et al., 2002). As well as sharing artefacts, learners may also discuss and co-construct artefacts in distributed constructionism (Resnick, 1996).

We argued that the theoretical alignment of constructionist theory and virtual world technology presented in this paper indicates that all features of constructionism can be supported by leveraging the features and perceived educational affordances of virtual worlds to inform a constructively aligned design of a constructionist learning experience in a virtual world. However, virtual worlds are typically not designed as learning environments, let alone to support constructionist learning. Additionally, unlike traditional digital constructionist learning environments, learners inhabit a shared space, represented by avatars and so there are questions as to the extent that these and other features and affordances of the technology would positively or negatively impact on the learners' experience of constructionist learning.

In this paper we have explored constructionist pedagogy in action, focusing on the experience of a group of learners. The findings and discussion have demonstrated for the first time how the features of the pedagogy emerge and how learners engage in meaningful artefact construction as they develop their knowledge and understanding in a purpose design learning activity. In this conclusion we identify the implications for theory, practice and future research.

Avatars emerged as an important cross-category theme. As previously mentioned, they are a key feature of virtual worlds; embodying users, facilitating social interaction and supporting a sense of immersion in a shared space. It is through the avatar that the user is seen by others to interact with objects and the physical space. As such the avatar becomes a key aspect of any learning experience in a virtual world. While they are not a feature of traditional digital constructionist environments, they may be considered to represent a near equivalent to a learner in a physical learning space such as a classroom. Yet the evidence shows that for some learners the avatar could become a barrier to learning. Additionally, we do not know how co-located learners use their avatars, whether they simply become a mediating tool for action within the virtual world or provide new opportunities.
The avatar has two key implications for constructionist learning experiences in virtual worlds. The first is that the acquisition of skills necessary to use the avatar may be a high-barrier for learners to master before they are able to engage in the learning experience. The second implication is that the avatar provides the learner with a sense of copresence with other users and therefore provides a unique opportunity to engage in distributed constructionism.

As avatars are an important feature of the technology and of particular relevance to distributed constructionism, further understanding of the role of the avatar in constructionist learning experiences in virtual worlds is necessary. By understanding how avatars support and limit learners, learning experiences can be designed to leverage the opportunities and reduce the limitations. While there is literature on the role of avatars in general, there is a need to examine their impact on the learner during constructionist learning experiences. Additionally, there is a need to understand better the barriers encountered by learners, whether these are skill-based or technical faults which may be considered to be first-order barriers (Ertmer, 1999), or located within the individual learner.

Resnick (1996) describes distributed constructionism as taking three forms: discussing, sharing and collaborating on constructions. The findings suggest that learners engaged in all three forms of distributed constructionism, facilitated through the creation of persistent objects and embodied social presence. In traditional constructionist environments, distributed constructionism is typically facilitated through asynchronous communication tools and the upload/download of artefacts. While this supports the sharing and discussing of artefacts, the construction of artefacts is limited as learners are unable to work on the same digital artefact at the same time. By comparison, virtual worlds support the synchronous sharing, discussing and co-construction of artefacts in-situ. While this appears to be afforded by the shared graphical environment and communication tools, a question remains as to the extent to which the avatar impacts on these activities, as both avatars and shared spaces for creating and observing are not features of traditional constructionist environments.

While there was evidence of collaboration on constructions in the findings, there was limited evidence of collaborative learning. Learners tended to work together, support each other in problem solving but they did not report learning together. Some groups that experienced an imbalance between partners may not have engaged in collaboration until they discussed the imbalance and how to resolve it, thus reducing opportunities for collaborative learning. It may also be possible that collaboration on constructions does not require collaborative learning or that the design of the learning activity did not promote this type of behavior. This raises questions about the appropriateness of the theoretical alignment of collaborating on constructions and collaborative learning. Instead, reconsidering the features and affordances which were found in this study to support collaboration on constructions and collaboration more generally, we propose that is the synchronous interactions within a shared space which allows learners to collaborate on constructions.

The public learning environment was of particular importance for collaboration on constructions, as well as sharing and discussing artefacts with others as they developed. While the original proposed alignment of persistence with the construction of a shareable artefact is supported by the findings of this study, the emerging perceived educational affordance of public or private learning environments is also significant in supporting the construction of shareable artefacts. This perceived educational affordance also appears to support distributed constructionism: discussing, sharing and collaborating on constructions. However, unlike sharing a completed artefact as per the Scratch website where learners can upload, discuss and share constructions, virtual worlds provide an opportunity to engage in the process of construction in a shared, synchronous, public environment. Thus learners can discuss, share and collaborate on constructions throughout the bricolage construction process and this may enhance opportunities for 
Table 3

Developed alignment of constructionism and the perceived educational affordances of virtual worlds.

\begin{tabular}{lll}
\hline Constructionism & Perceived educational affordances \\
\hline $\begin{array}{c}\text { Construct personally meaningful } \\
\text { artefacts }\end{array}$ & $\begin{array}{l}\text { Creation of persistent } \\
\text { objects }\end{array}$ & Construction \\
$\begin{array}{c}\text { Actively explore, test and extend } \\
\text { understanding }\end{array}$ & & \\
$\begin{array}{l}\text { Opportunity to program } \\
\text { Shareable artefact }\end{array}$ & & Programming \\
Bricolage & Public/private learning environments \\
In-situ & Flexibility & \\
'Invisible' technology & Embodied social presence & \\
Collaborating on constructions & Immersion & Synchronous interactions in shared \\
& spaces & \\
& &
\end{tabular}

learning. Currently there is limited understanding in the literature on constructionism of the impact of sharing early constructions with others during the bricolage construction process online. Further research in virtual worlds may provide a particularly advantageous environment to study this issue, both in terms of how it is designed for and the impact it has on learning.

The activity underpinning this study was designed by aligning the principles of constructionism with an analysis of the perceived educational affordances of virtual worlds. This study has allowed us to refine this theoretical alignment in two ways. Firstly, the virtual world affords a public and private learning environment that supports the constructionist characteristic of a shareable artefact thus extending the perceived educational affordances of a virtual world. Secondly the virtual world affordance of collaborative learning has been refined and replaced by the affordance of synchronous interaction in shared spaces representing then finding that learners did not necessarily engage in collaborative learning.
Thus Table 3 presents the revised alignment of pedagogy and educational affordances as informed by this study, with the amendments in bold.

This paper has provided the first insights into how learners engage in meaningful artefact construction through a constructionist learning activity in virtual worlds. It has identified implications for theory, practice and future research, regarding the role of the avatar, the sharing of early and incomplete constructions, as well as the use of public/private learning environments, with regard to the transformation of traditional constructionist activities. Finally, it demonstrates the potential of leveraging the features and affordances of virtual worlds to provide opportunities for learners to engage in distributed constructionist activities in new ways. We argue that appropriating emerging technologies for constructionist learning requires us to move beyond simply replicating traditional constructionist tools and environments and instead requires us to be open to new and unexpected potentialities of the technology to transform constructionist learning.

\section{Declaration of interest}

The funders had no direct input into the study, the writing of any report or the decision to submit the paper for publication.

\section{Acknowledgements}

The authors would like to thank members of the Centre for Research in IT in Education, Trinity College, University of Dublin for their support throughout this study and the students who gave their time to participate in the research. Funding was provided through the 'Embark Initiative' of the Irish Research Council for Science Engineering and Technology. The authors would also like to thank colleagues in the School of Social Sciences at Cardiff University for their support during the preparation of this paper.

\section{Appendix}

The Appendix presents the final codes, minor themes, and sub-categories of the categories 'Group Work' (Table 4), 'Learning environment and design' (Table 5) and 'Learning' (Table 6) which emerged through the constant comparative analysis.

Table 4

Category of 'group work' and associated sub-categories and codes.

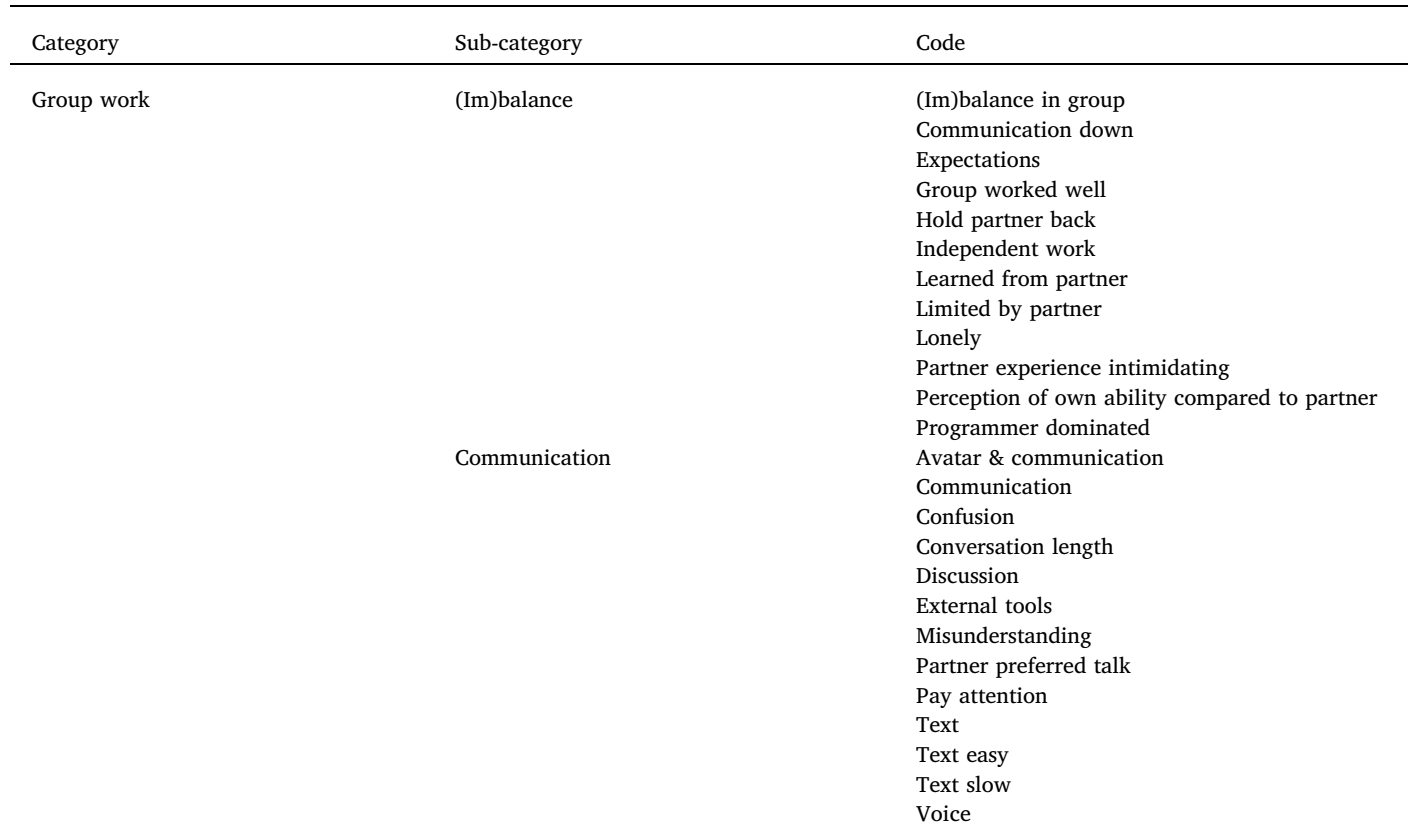


Table 4 (continued)

\begin{tabular}{ll}
\hline Category & Code \\
\hline Collaboration & (A)synchronous collaboration \\
& Avatar supports collaboration \\
Collaboration & Collaboration hindered by SL constraint \\
& Collaboration on unfamiliar task \\
& Face-to-face collaboration \\
& Insight into collaboration \\
& Online collaboration \\
& Partner influence \\
& Real life influence \\
& Roles \\
Sharing scripts \\
Unable to observe partner \\
& Virtual an obstacle to collaboration \\
& Worked well together \\
\hline
\end{tabular}

Table 5

Category of 'group work' and associated sub-categories, minor theme and codes.

Category Sub-category $\quad$ Minor theme Code

Learning environment

Design
3D

Avatar - Identity

Avatar - sense of presence/inhabiting

Avatar supports experience

Immersion - avatar

Immersion - SL

Immersion - SLurtle

Influence of presentation space

'Physical' mediated through avatar

Avatar supports building

Complexity

Creative

Design

Design influences

Design theme or concept

Develop idea

Disappointment

Expectations

Exploring

Exploring SLurtles

Frustration

Idea

Initial ideas

Planning

Playing

Sense of achievement

Starting afresh

Structured exploration

Unchanging

User perception

User experience

Avoiding other groups

Influence of other groups - not looking

Influencing others

Invisible

Looking at other groups' work

Make public

Public

Walls

Challenges

Design influence

Fun

Influence of looking at other groups' work

Influence of outsider perception

Influencing others

Motivation

Others visiting

Personal sources of motivation

Seeing other groups' work

(continued on next page) 
Table 5 (continued)

\begin{tabular}{|c|c|c|c|}
\hline Category & Sub-category & Minor theme & Code \\
\hline & & Socialising & $\begin{array}{l}\text { Avatar - sense of presence } \\
\text { Avatar supports socialising } \\
\text { Avoiding other groups } \\
\text { Etiquette } \\
\text { Others visiting } \\
\text { Pressure } \\
\text { Socialising }\end{array}$ \\
\hline
\end{tabular}

Table 6

Category of 'learning' and related sub-categories and codes

\begin{tabular}{|c|c|c|}
\hline Category & Sub-category & Code \\
\hline \multirow[t]{18}{*}{ Learning } & Learning in order to participate & SL skill learning \\
\hline & & Learning S4SL to SL skills \\
\hline & Learning through the learning experience & Insight into collaboration \\
\hline & & Learning about reflection \\
\hline & & Learning about self \\
\hline & & Learning beyond programming \\
\hline & & Portable knowledge \\
\hline & & SLurtle building \\
\hline & & Teacher identity \\
\hline & How they learned & Avatar \& viewing angles support learning \\
\hline & & Learning from partner \\
\hline & & Learning together \\
\hline & & More knowledgeable other \\
\hline & & Partner affected learning \\
\hline & & Partner influence \\
\hline & & Reflection \\
\hline & & Sharing ideas between partners \\
\hline & & Visiting other groups - learning \\
\hline
\end{tabular}

\section{References}

Ackerman, E. (2004). Constructing knowledge and transforming the world. In M. Tokoro, \& L. Steels (Eds.). A learning zone of one's own: Sharing representations and flow in collaborative learning environments (pp. 15-37). Oxford: IOS Press.

Ackerman, E., \& Strohecker, C. (1999). Build, launch, convene: Sketches for constructivedialogic learning environments. MERL - A Mitsubishi electric research Laboratory. Retrieved $25^{\text {th }}$ October 2009, from http://www.merl.com/papers/TR99-30/.

Boeije, H. (2002). A purposeful approach to the constant comparative method in the analysis of qualitative interviews. 2002 Quality and Quantity, 36(4), 391-409.

Brown, E., \& Cairns, P. (2004). A grounded investigation of game immersion. Proceedings of the conference on human factors in computing systems (CHI 2004) (pp. pp12791300). New York: ACM Press.

Bruckman, A., \& Resnick, M. (1996). The MediaMoO project: Constructionism and professional community. In Y. Kafai, \& M. Resnick (Eds.). Constructionism in practice: Designing thinking, and learning in a digital world (pp. 207-222). New Jersey: Lawrence Erlbaum Associates.

Butler, D. (2007). A constructionist view on what it means to be digitally literate. Nordic Journal of Digital Literacy, 2, 61-77.

Cheal, C. (2009). Student perceptions of a course taught in Second Life. Innovate Journal of Online Education, 5(5).

Cohen, L., Manion, L., \& Morrison, K. (2007). Research methods in education (6 ${ }^{\text {th }}$ ed.). London: Routledge.

Creswell, J. W. (2003). Research Design: Qualitative, quantitative and mixed methods approaches ( $2^{\text {nd }}$ ed.). London: Sage.

Dalgarno, B., \& Lee, M. J. W. (2010). What are the learning affordances of 3-D virtual environments? British Journal of Educational Technology, 41(1), 10-32.

Dickey, M. D. (2005). Brave new (interactive) worlds: A review of the design affordances and constraints of two 3D virtual worlds as interactive learning environments. Interactive Learning Environments, 13(1-2), 121-137.

Dickey, M. D. (2011). World of Warcraft and the impact of game culture and play in an undergraduate game design course. Computers \& Education, 56(1), 200-209.

Dreher, C., Reiners, T., Dreher, N., \& Dreher, H. (2009). Virtual worlds as a context suited for information systems education: Discussion of pedagogical experience and curriculum design with reference to second life. Journal of Information Systems Education, 20(2), 211-224.

Dreher, H., Reiners, T., Dreher, C., \& Dreher, N. (2009b). 3D spaces in software engineering: From K-12 to life long learning. World conference on educational multimedia, hypermedia and telecommunications. Vol. 2009. World conference on educational multimedia, hypermedia and telecommunications (pp. 4103-4112). No. 1.

Edwards, L. D. (1998). Embodying mathematics and science: Microworlds as representations. Journal of Mathematical Behaviour, 17(1), 53-78.

Ertmer, P. A. (1999). Addressing first-and second-order barriers to change: Strategies for technology integration. Educational Technology Research and Development, 47(4), 47-61.

Faiola, A., \& Smyslova, O. (2009). Flow experience in Second Life: The impact of telepresence on human-computer interaction. In A. A. Ozok, \& P. Zaphiris (Eds.). Online communities (pp. 574-583). Berlin: Springer.

Feurzeig, W. (2007). Towards a culture of creativity: A personal perspective on logo's early years, legacy, and ongoing potential. In I. Kalaš (Ed.). Proceedings of EuroLogo 2007. Bratislava, august 2007.

Fominykh, M., Prasolova-Førland, E., \& Divitini, M. (2014). Creative collaboration in a 3D virtual world: Conducting educational activities, designing environments, and preserving results. In D. Sampson, D. Ifenthaler, M. Spector, \& P. Isaias (Eds.). Digital systems for open access to formal and informal learning (pp. 257-274). Cham: Springer.

Gamage, V.,Tretiakov, A. \& Crump, B. (2011). Teacher perceptions of learning affordances of multi-user virtual environments. Computers \& Education, 57(4), 2406-2413.

Ghanbarzadeh, R., \& Ghapanchi, A. H. (2018). Investigating various application areas of three-dimensional virtual worlds for higher education. British Journal of Educational Technology, 49(3), 370-384.

Girvan, C. (2014). Constructionism, creativity and virtual worlds. In G. Futschek, \& C Kynigos (Eds.). Constructionism and creativity: Proceedings of the 3rd international constructionism conference 2014 (pp. p367-377). Vienna, Austria: Austrian Computer Society.

Girvan, C. (2018). What is a virtual world? Definition and classification. Educational Technology Research \& Development, 66(5), 1087-1100.

Girvan, C., \& Savage, T. (2010). Identifying an appropriate pedagogy for virtual worlds: A communal constructivism case study. Computers \& Education, 55(1), 342-349.

Girvan, C., \& Savage, T. (2012). Ethical considerations for educational research in a virtual world. Interactive Learning Environments, 20(3), 239-251.

Girvan, C., Tangney, B., \& Savage, T. (2013). SLurtles: Supporting constructionist learning in second life. Computers \& Education, 61, 115-132.

Glaser, B. G., \& Strauss, A. L. (1967). The discovery of grounded theory. Chicago: Aldine.

Gregory, S., Scutter, S., Jacka, L., McDonald, M., Farley, H., \& Newman, C. (2015). Barriers and enablers to the use of virtual worlds in higher education: An exploration of educator perceptions, attitudes and experiences. Educational Technology \& Society, 18(1), 3-12.

Grinberg, A. M., Careaga, J. S., Mehl, M. R., \& O'Connor, M. F. (2014). Social engagement and user immersion in a socially based virtual world. Computers in Human Behavior, $36,479-486$.

Grivokostopoulou, F., Perikos, I., Kovas, K., \& Hatzilygeroudis, I. (2016, March). Learning approaches in a 3D virtual environment for learning energy generation from renewable sources. FLAIRS conference (pp. 497-500). . 
Holmes, B., Tangney, B., FitzGibbon, A., Savage, T., \& Mehan, S. (2001). Communal Constructivism: Students constructing learning for as well as with others. Proceedings of SITE 2001. Retrieved August 23, 2007, from http://www.cs.tcd.ie/publications/ techreports/reports.01/TCD-CS-2001-04.pdf.

Hoyles, C., Noss, R., \& Adamson, R. (2002). Rethinking the microworld idea. Journal of Educational Computing Research, 27(1), 29-53.

Kafai, Y. B. (2006). Constructionism. In R. K. Sawyer (Ed.). The cambridge handbook of the learning sciences (pp. pp35-46). Cambridge: Cambridge University Press.

Kafai, Y. B., \& Resnick, M. (1996). Constructionism in practice: Designing, thinking and learning in a digital world. Mahwah, NJ: Lawrence Erlbaum Associates, Publishers.

Livingstone, D., Scullion, J., \& Creechan, G. (2013). Learning about collaborative virtual environments by creating collaborative virtual environments, Vol. 3, London, UK: King's College149 London, 28-29 November 2013.

Merriam, S. B. (1998). Qualitative research and case study applications in education. San Francisco: Jossey-Bass.

Mezirow, J. (1996). Contemporary paradigms of learning. Adult Education Quarterly, 46, 158-172.

Niemeyer, D. J., \& Gerber, H. R. (2015). Maker culture and minecraft: Implications for the future of learning. Educational Media International, 52(3), 216-226.

Papert, S. (1980). Mindstorms: Children, computers and powerful ideas. New York: Basic Books.

Papert, S. (1980s). Constructionism vs. instructionism. Retrieved January 10, 2008, from http://papert.org/articles/const_inst/const_inst1.html.

Papert, S. (1991). Situating constructionism. In I. Harel, \& S. Papert (Eds.). Constructionism (pp. 1-14). Hillsdale, NJ: Lawrence Erlbaum Associate.

Pellas, N., \& Peroutseas, E. (2016). Gaming in Second Life via Scratch4SL: Engaging high school students in programming courses. Journal of Educational Computing Research, 54(1), 108-143.

Resnick, M. (1996). Distributed constructionism. In D. C. Edelson, \& E. A. Domeshek
(Eds.). Proceedings of the 1996 international conference on learning sciences (pp. 280284). .

Resnick, M., Maloney, J., Monroy-Hernández, A., Rusk, N., Eastwood, E., Brennan, K., et al. (2009). Scratch: Programming for all. Communications of the ACM, 52(11), 60-67.

Rosenbaum, E. (2008). Scratch for second life. In S. Veeragoudar Harrell (Ed.). Virtually there: Emerging designs for STEM teaching and learning in immersive online 3D microworlds. Symposium in Proceedings of the International Conference on Learning Sciences ICLS 2008Utrecht, The Netherlands: ICLS. Abstract retrieved February 1, 2010, from http://www.fi.uu.ul/en/icls2008/144/paper144.pdf.

Salomon, G. (1994). Distributed cognition. Cambridge: Cambridge University Press. Sanchez, J. (2007). Second life: An interactive qualitative analysis. In C. Crawford, (Ed.) Proceedings of society for information technology and teacher education international conference 2007 (pp. 1240-1243). Chesapeake, VA: AACE.

Savin-Baden, M. (2008). From cognitive capability to social reform? Shifting perceptions of learning in immersive virtual worlds. ALT-J, 16(3), 151-161.

Savin-Baden, M., Tombs, C., Poulton, T., Conradi, E., Kavia, S., Burden, D., et al. (2011) An evaluation of implementing problem-based learning scenarios in an immersive virtual world. International Journal of Medical Education, 2, 116-124.

Strauss, A. L., \& Corbin, J. M. (1998). Basics of qualitative research: Techniques and procedures for developing grounded theory. Thousand Oaks: Sage Publications.

Taylor, T. L. (2002). Living digitally: Embodiment in virtual worlds. In R. Schroeder (Ed.). The social Life of avatars: Presence and interaction in shared virtual environments. London: Springer-Verlag.

Warden, C. A., Stanworth, J. O., \& Chang, C. C. (2016). Leveling up: Are non-gamers and women disadvantaged in a virtual world classroom? Computers in Human Behavior, 65, 210-219.

Yin, R. K. (2003). Applications of case study research. Thousand Oaks, CA: Sage.

Yin, R. K. (2009). Case study research: Design and methods. Thousand Oaks, CA: Sage. 